\title{
Doxorubicin Kinetics and Effects on Lung Cancer Cell Lines Using In-vitro Raman Micro-Spectroscopy: Binding Signatures, Drug Resistance and DNA Repair
}

\author{
Hugh J. Byrne \\ Technological University Dublin, hugh.byrne@tudublin.ie \\ Franck Bonnier \\ Technological University Dublin, Franck.Bonnier@tudublin.ie \\ Alan Casey \\ Technological University Dublin, alan.casey@tudublin.ie
}

See next page for additional authors

Follow this and additional works at: https://arrow.tudublin.ie/biophonart

Part of the Medicine and Health Sciences Commons

\section{Recommended Citation}

Byrne, H.J., Bonnier, F. \& Farhane, Z. (2017). Doxorubicin kinetics and effects on lung cancer cell lines using in-vitro Raman micro-spectroscopy: binding signatures, drug resistance and DNA repair. Journal of Biophotonics, vol. 10, no. 6. doi:10.1002/jbio.201700060

This Article is brought to you for free and open access by the DIT Biophotonics and Imaging at ARROW@TU Dublin. It has been accepted for inclusion in Articles by an authorized administrator of ARROW@TU Dublin. For more information, please contact arrow.admin@tudublin.ie, aisling.coyne@tudublin.ie,gerard.connolly@tudublin.ie.

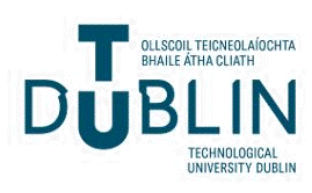




\section{Authors}

Hugh J. Byrne, Franck Bonnier, Alan Casey, Orla L. Howe, and Zeineb Farhane

This article is available at ARROW@TU Dublin: https://arrow.tudublin.ie/biophonart/33 


\title{
Monitoring Doxorubicin cellular uptake and trafficking using in vitro Raman micro-spectroscopy: short and long time exposure effects on lung cancer cell lines
}

\author{
Z.Farhane $^{1 *}$, F.Bonnier ${ }^{2}$ and H.J.Byrne ${ }^{1}$
}

${ }^{1}$ FOCAS Research Institute, Dublin Institute of Technology, Kevin Street, Dublin 8, Ireland.

${ }^{2}$ Université François-Rabelais de Tours, Faculty of Pharmacy, EA 6295 Nanomédicaments et Nanosondes, 31 avenue Monge, 37200 Tours, France

*Correspondingauthor: zeineb.farhane@mydit.ie

\begin{abstract}
:
Raman micro-spectroscopy is a non-invasive, in vitro analytical tool which is being increasingly explored for its potential in clinical applications and monitoring the uptake, mechanism of action and cellular interaction at a molecular level of chemotherapeutic drugs, ultimately as a potential label-free preclinical screening and companion diagnostic tool.

In this study, Doxorubicin (DOX), a "gold standard" chemotherapeutic drug, is employed as a model in the in vitro lung cancer cell line, A549, in order to demonstrate the potential of Raman micro-spectroscopy to screen and identify spectroscopic markers of its trafficking and mechanism of action. Confocal Laser Scanning Microscopy (CLSM) was used in parallel to illustrate the uptake and subcellular localisation, and cytotoxicity assays were employed to establish the toxicity profiles for early and late exposure times of A549 to DOX. Multivariate statistical analysis, consisting of principal components analysis (PCA), partial least squares regression (PLSR) and independent component analysis (ICA) were used to elucidate the spectroscopic signatures associated with DOX uptake and subcellular interaction.

Raman spectroscopic profiling illustrates both drug kinetics and its pharmacodynamics in the cell and associated biochemical changes, demonstrating that DOX is mainly localised in the nuclear area, saturating the nucleolus first, within $\sim 6 \mathrm{hrs}$ of exposure, before the surrounding nuclear areas after $\sim 12 \mathrm{hrs}$, and only accumulates in the cytoplasm after $48 \mathrm{hrs}$. PLSR over varying time intervals enables identification of DOX-DNA binding at early stages of exposure (0-12hrs), while regression over the longer time periods (24-72hrs) reveals spectroscopic signatures associated with the metabolic cellular response.
\end{abstract}


Keywords: Raman micro spectroscopy, Confocal Laser Scanning Microscopy, Doxorubicin, cytotoxicity, long and short time exposure, Multivariate Analysis. 


\section{Introduction:}

Doxorubicin (DOX), a cell cycle non-specific chemotherapeutic agent, is one of the two first anthracycline antibiotics isolated from Streptomyces peucetius (1) and among the most widely used chemotherapeutic agents, despite its numerous side effects, $(2,3)$ and is highly effective in treating different types of cancers, from leukaemia, thyroid, and lung to many other neoplasia, especially metastatic and invasive ones. (3-6) The accepted mechanisms of action of DOX are complex and not fully understood, and include the interaction (i) with the cellular nuclear area, consisting of DNA intercalation, cross-linking, binding and alkylation, inhibition of topoisomerase I and II and RNA polymerase, all inducing DNA damage, inhibition of DNA replication and protein synthesis (rRNA transcription inhibition), as a consequence, leading to nucleolar disruption and cellular apoptosis (7) and (ii) with the cell membrane and mitochondria, resulting in generation of reactive oxygen species leading to direct membrane damage and oxidative stress, responsible for the major DOX side effect, cardiomyopathy.(3, 8-10) DNA remains the main target of cancer therapeutics, whereby induction of DNA damage initiates a cascade of events that determines cellular apoptosis. DNA damage level and repair, by expression of anti-apoptotic proteins such as bcl-2 and resistance to apoptosis, are the main processes involved in carcinogenesis and in the response of cancer cells to cancer chemotherapy.(11, 12)

Apoptosis, known as programmed cell death, plays an important role in the internal environmental homeostasis and is closely associated with the development of cancer and in chemotherapy, by implication, of drug-induced cell apoptosis.(13) One of the pathways leading to apoptosis disruption and tumour development is the nucleolar stress pathway.(14) In fact, the nucleolus, known also as a ribosome factory, is the most prominent structure inside the nucleus, acting as a central integration of signalling pathways and performing numerous functions such as production of ribosome subunits, RNA editing and cell cycle and playing an important role in cancer development by dysregulation of its functions. (15-17) Due to its fundamental contribution in cancer proliferation, the nucleolus is the target for chemotherapeutic drugs such as Actinomycin D, which inhibits rRNA synthesis, Cisplatin which interferes with RNA Polymerase I in the nucleolus decreasing rDNA transcription, 5fluoruracil which targets rRNA processing, DNA/RNA synthesis and DNA repair and DOX, which is known to disrupt nucleolar morphology and decrease rDNA transcription. $(14,18)$ It has also been shown in previous Raman spectroscopic studies that this sub-nuclear region is responsible for the discrimination between cancer cell lines.(19) 
Among the most common cancers worldwide, lung cancer is by far the highest cause of cancer-related death and has a 5-year survival of $15 \%$.The main treatments of lung cancer are chemotherapy and radiotherapy, but these approaches have serious side effects and drug resistance is often developed during treatment.(20) Thus, a better understanding of the mechanism of drug action and the cellular responses at the pre-clinical step is crucial to improve patient survival. To this end, Raman micro spectroscopy, a non-invasive powerful label-free in vitro screening tool, is presented as the ideal candidate due to its ability to detect chemical, biological and physical changes of biomolecules at subcellular level and provide a molecular fingerprint of the sample of interest, in this case cancer cell physiology, at a subcellular level, during chemotherapeutic treatment.(21-24)

Raman micro spectroscopy has attracted considerable attention over the last few years in the pharmaceutical field to aid in areas such as the drug discovery process, quality control during industrial manufacturing and detection of counterfeit products, $(23,25,26)$ and well as its possible clinical applications. $(27,28)$ Its potential as a screening technique either for normal and cancer cell discrimination or in chemotherapeutic and cellular process screening has been demonstrated. $(19,29)$

Therefore, it can be developed as a companion diagnostic tool, providing details about drug efficacy and safety, as detailed in the US FDA guidance document issued in August 2014, which defines such a tool as an in vitro diagnostic device that provides information that is essential for the safety and efficacy of a corresponding therapeutic product.(30, 31)

The demonstration of Raman micro spectroscopy as a companion diagnostic for screening and analysis of commercial chemotherapeutic agents could be of significant importance in cancer research and especially in pre-clinical in vitro screening, a concept introduced by the US National Cancer Institute (NCI) in 1955 and providing screening models and supports to research, as a model which accurately predicts drug efficacy accurately at a molecular level, clinical activity and pharmacodynamics and kinetics. $(32,33)$

Previously, DOX, routinely used for lung cancer therapy, was employed with A549, a nonsmall lung cancer cell line, and Raman analysis of the distribution of the drug in the cell, and the changes in the cellular spectroscopic signatures was performed, at a fixed point in time (24hrs). (29)

In the present paper, investigations were extended to look at the evolution of the responses, in order to track the drug reactions for early and late stages exposure, globally understand the mechanism of action and monitor the subsequent cellular behaviour using Raman microspectroscopy. The study demonstrates the potential of Raman Spectroscopy to monitor the 
drug uptake and the cellular responses at a subcellular level, but also elucidate details of the pharmacodynamics and drug cellular kinetics of the clinically prescribed drug.

\section{Materials and methods:}

\subsection{Materials:}

A549 human lung adenocarcinoma cells with the alveolar type II phenotype were obtained from ATCC (Manassas, VA, USA).

Doxorubicin hydrochloride ${ }^{\circledR}$ powder (Sigma Life Sciences, Ireland) was diluted in $1 \mathrm{~mL}$ sterile water to the required concentration $(17.25 \mathrm{mM})$.

Alamar blue $(\mathrm{AB})$ (10X ready to use solution) and 3-[4,5-dimethylthiazol-2-yl]-2,5-diphenyl tetrazolium bromide (MTT) were obtained from Sigma Aldrich, Ireland.

For cytotoxicity assays, an AB/MTT solution, $1.5 \mathrm{~mL}$ of $\mathrm{AB}$ and $3 \mathrm{~mL}$ of MTT stock solution $(2.5 \mathrm{mg} / \mathrm{mL}, 25 \mathrm{mg}$ MTT/10mL PBS) in $30 \mathrm{~mL}$ of fresh medium was prepared prior to the tests.

\subsection{Cell culture}

A549 cells were cultured in DMEM (with $2 \mathrm{mM}$ L-glutamine) with $10 \%$ foetal bovine serum (FBS) at $37^{\circ} \mathrm{C}$ in a humidified atmosphere containing $5 \% \mathrm{CO}_{2}$ and cells were split every two days to maintain $\sim 60 \%$ confluence.

For Confocal Laser Scanning Fluorescence Microscopy (CLSM) and Raman micro spectroscopic analysis, cell number was determined using a Beckman Coulter Particle Count and Size Analysis ${ }^{\circledR}$ Z2Cell Counter.

\subsection{Cytotoxicity assays:}

$\mathrm{AB}$ and MTT assays were performed in 96 well plates and a total number of $1 \times 10^{5} / 25 \mathrm{~mL}$, $1 \times 10^{4} / 25 \mathrm{~mL}$ and $5 \times 10^{3} / 25 \mathrm{~mL}$ cells, respectively for $0-24 \mathrm{hrs}$, $48 \mathrm{hrs}$ and $72 \mathrm{hrs}$ DOX exposure, were used to seed three plates each. After $24 \mathrm{hrs}$ incubation, plates were washed with phosphate buffered saline solution (PBS) and DOX was added in a concentration range from $0 \mu \mathrm{M}$ (as a control) to $50 \mu \mathrm{M}$.

$\mathrm{AB}$ and MTT assays were both measured with a Cytotox SpectraMax ${ }^{\circledR} \mathrm{M} 3$ plate reader using Soft Max ${ }^{\circledR}$ Pro6.2.2 software. After incubation in DOX, plates were washed with PBS and 
$100 \mu \mathrm{L}$ of AB/MTT solution were added to each well. Plates were then incubated for 3 hours and $\mathrm{AB}$ fluorescence was measured first in the plate reader using $540 \mathrm{~nm}$ excitation and $595 \mathrm{~nm}$ emission, then the medium was removed, the plates were washed with PBS and $100 \mu \mathrm{L}$ of DMSO (Dimethyl sulfoxide) were added in each well. MTT absorbance was read at $570 \mathrm{~nm}$.

All cytotoxicity assays were made in triplicate and repeated three times and viability data was fitted by a four parameter Hill equation analysis using SigmaPlot 10.0, to yield values of the mean inhibitory concentration, $\mathrm{IC}_{50}$.

\subsection{Confocal Laser Scanning Fluorescence Microscopy:}

Approximately $1 \times 10^{4}$ cells were allowed to attach on uncoated glass bottom Petri dishes (MatTek Corporation, USA) for two hours, after which they were covered with cell culture medium. After $24 \mathrm{hrs}$ incubation, the medium was removed and samples were rinsed twice with sterile PBS, new fresh medium containing DOX corresponding to the inhibitory concentration, $\mathrm{IC}_{50}$, determined by cytotoxicity assays for each time point (48 and $72 \mathrm{hrs}$ ) and adjusted to the cell number (Table 1), was added and cells were incubated for a further $48 \mathrm{hrs}$ and $72 \mathrm{hrs}$ separately. For short time exposure, cells were incubated with the inhibitory concentration, $\mathrm{IC}_{50}$ determined previously for $24 \mathrm{hrs}$, and samples corresponding to each time point, 2, 6, 12 and 24hrs were prepared separately. After incubation, samples were rinsed twice with sterile PBS, fixed in formalin $(4 \%, 15 \mathrm{mn})$ and kept in PBS for imaging. Control samples without exposure to DOX were also prepared in parallel, and incubated for 2, 6, 12, 24, 48 and 72 hrs.

CLSM images were recorded using an inverted Zeiss LSM 510 confocal laser scanning microscope equipped with a x60 oil immersion objective. DOX fluorescence was excited with an argon ion laser at $488 \mathrm{~nm}$, and the emission was collected at $530 \mathrm{~nm}$.

\subsection{Raman micro spectroscopy:}

Cells ( 1x 10 /window) were seeded and incubated on $\mathrm{CaF}_{2}$ windows (Crystan Ltd, UK) for $24 \mathrm{hrs}$ for both control and exposure to DOX. Medium was then removed and samples were rinsed twice with sterile PBS and covered with DOX at each corresponding IC $_{50}$ inhibitory concentration $\left(\mathrm{IC}_{50}(24 \mathrm{hr})\right.$ for 2, 6, 12, $24 \mathrm{hr}$ exposure, $\mathrm{IC}_{50}(48 \mathrm{hr})$ and $\mathrm{IC}_{50}(72 \mathrm{hr})$ ) which is normalised according to the cell number used ( 1 x 10\% /window) (Table1). The $24 \mathrm{hr} \mathrm{IC}_{50}$ dose was initially chosen, based on previous studies (12), in order to monitor the kinetics of the 
uptake of DOX at earlier times. This dose was reduced for $48 \mathrm{hr}$ and $72 \mathrm{hr}$ exposures, as it would be too toxic at the longer exposure times.

After each incubation period (2, 6, 12, 24, 48 and $72 \mathrm{hrs}$ ), cells were washed twice with sterile PBS and fixed in formalin (4\%, 15min).

A Horiba Jobin-YvonLabRAM HR800 spectrometer with a 785nm, 300mW diode laser as source ( $\sim 100 \mathrm{~mW}$ at the sample), Peltier cooled 16-bit CCD, 300 lines/mm grating and 100 $\mu \mathrm{m}$ confocal hole, was used for this work. Spectra were acquired in the range from $400 \mathrm{~cm}^{-1}$ to $1800 \mathrm{~cm}^{-1}$ using a x100 objective (LCPlanN, Olympus), in dry conditions, for 30s twice, from three cell locations: cytoplasm, nucleus and nucleolus, to finally produce a data set of 30 points per cell location for each time point, 2, 6, 12, 24, 48 and 72hrs after DOX exposure and for control cells, over a total of 210 cells corresponding to a total data set of 630 spectra.

\subsection{Data analysis:}

Raman spectral pre-processing and analysis were performed in Matlab 2013 using algorithms developed in house. Prior to analysis, background was subtracted using a NCLS (nonnegatively constrained least squares) algorithm and spectra were subsequently smoothed (Savitsky-Golay filter 3th order, 11 points), baseline corrected (fifth order polynomial) and vector normalised.

Principal components analysis (PCA) was employed as an unsupervised multivariate approach to analyse data and the effects of doxorubicin in each cell localisation. The order of the PCs denotes their importance to the dataset and PC1 describes the highest amount of variation.(34)

Partial least squares regression (PLSR) was employed to track the temporal and dose dependent evolution of the spectral signatures in the subcellular regions. PLSR is a statistical regression technique which reduces the dimensionality of the data and correlates information in an $X$ data set matrix to the matrix of a $Y$ data according to the equation $\mathrm{Y}=\mathrm{XB}+\mathrm{E}$, where $\mathrm{B}$ is a matrix of regression coefficients and $\mathrm{E}$ is the regression residual. In this work, the $\mathrm{X}$ matrix is represented by the Raman spectra and the Y-matrix is consisted of values of the DOX concentration inside the cells, and the time evolution.(35-37)

The percentage of variance explained in the response variable $(\mathrm{Y})$ as a function of the number of components was calculated using 10-fold cross validation and from a plot of the percent of variance explained function of number of components, the majority percentage of variance (above 90\%) was found to be explained by the first 3 components. 
The regression coefficients obtained by PLSR of Raman data regressed separately against DOX cellular concentration and time evolution were plotted and analysed. As a function of frequency, the co-efficients illustrate the spectral features which are influenced by the intracellular interaction of the DOX and the resulting metabolic changes.

Independent component analysis (ICA), a signal-processing technique, was also employed as an extension to PCA. ICA is an unsupervised statistical technique able to identify latent and statistically independent variables called independent components and corresponding to the pure signal underlying the observed signal and to interpret their different contributions. In the case of Raman micro spectroscopy, ICA can be used to identify and extract principal spectral contributions such as those from substrate, using the same number of ICs (independent components) as PCs which is three components, which can then be removed or studied in their own right.(12, 38-40) The first independent component (IC1) explains the highest percentage of variance and was used to further examine the temporal evolution of the spectral signatures.

\section{Results:}

\subsection{Cytotoxicity assays:}

The cytotoxicity of A549 cells to DOX exposure using both the AB and MTT assays for 24hrs has been previously reported (29), indicating an $\mathrm{IC}_{50}$ of $0.42 \pm 0.06 \mu \mathrm{M}$ and $0.55 \pm$ $0.16 \mu \mathrm{M}$ for $\mathrm{AB}$ and MTT, respectively. Figure S1 of the supplementary information shows the dose dependant cytotoxicity of DOX after 48hrs (Figure S1A) and 72hrs (Figure S1B) exposure, for the A549 cell line, according to the AB and MTT in vitro cytotoxicity assays. Viability is expressed as \% compared to control (non-exposed healthy cells), and the error bars indicate the standard deviation of six independent replicate measurements. For both in vitro assays and for all times exposure, a partial loss of cell population viability is observed.

The AB and MTT assays for the A549 cell line show similar responses for late time exposure (48 and $72 \mathrm{hrs}$ ) but slightly different ones for $24 \mathrm{hrs}$. However, the $\mathrm{IC}_{50}$ values for $48 \mathrm{hrs}$ exposure for A549 cells are comparable and were determined to be $0.30 \pm 0.04 \mu \mathrm{M}$ and $0.31 \pm$ $0.05 \mu \mathrm{M}$ for $\mathrm{AB}$ and MTT, respectively. Similar behaviour was found after $72 \mathrm{hrs}$ treatment, characterised by $\mathrm{IC}_{50}$ values of $0.29 \pm 0.02 \mu \mathrm{M}$ and $0.27 \pm 0.02 \mu \mathrm{M}$, respectively for $\mathrm{AB}$ and MTT. 
The MTT assay is a reflection of mitochondrial activity while the AB assay is the expression of general cellular metabolism. The somewhat greater sensitivity of MTT compared to AB at the early stages is consistent with a mechanism of interaction which induce an early apoptosis. $(41,42)$ Nevertheless, since the mechanisms and cellular effects for the long time exposures of 48 and $72 \mathrm{hrs}$ will be compared to those for shorter exposures $0-24 \mathrm{hrs}$, the $\mathrm{IC}_{50}$ determined by the MTT assay was used throughout the study for comparability purposes and Figure 1 shows the dose dependant cytotoxicity for those time points.

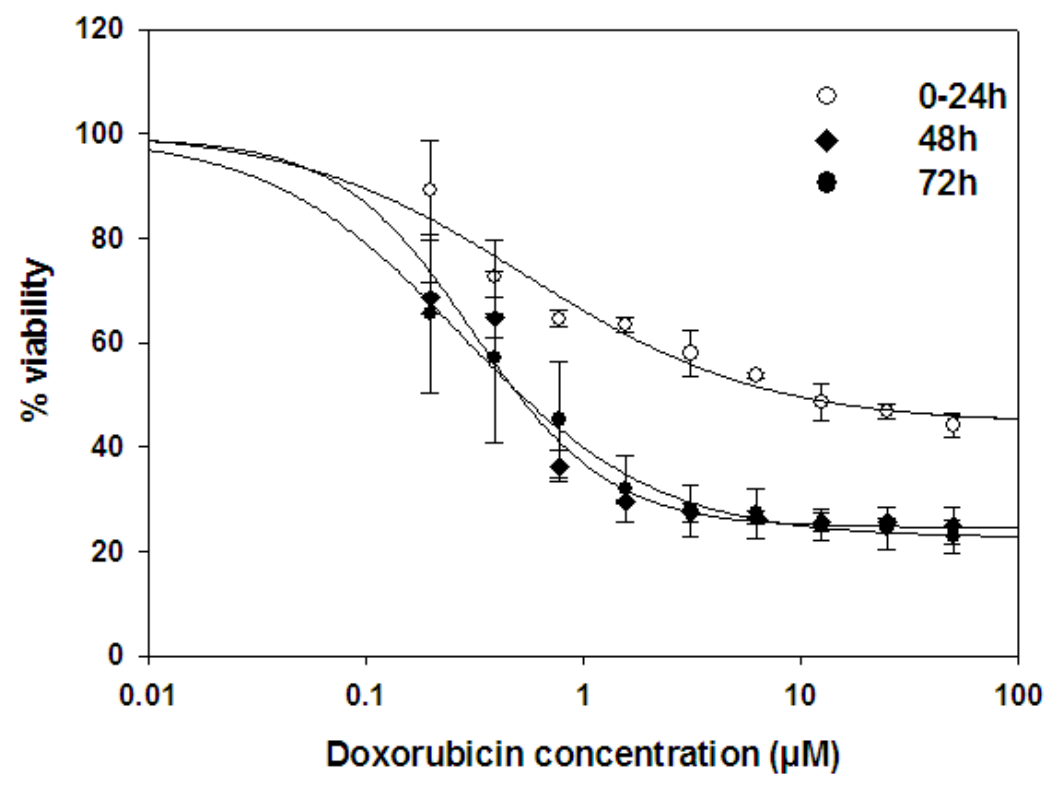

Figure 1: MTT in vitro dose dependent cytotoxicity assays of DOX to A549 cell line for short (0-24hr) and long exposure times (48hrs, 72hrs).Viability is expressed as \% compared to control, and the error bars indicate the standard deviation of six independent replicate measurements

For Raman micro spectroscopy and Confocal Laser Scanning Fluorescence Microscopy, the DOX dose used was scaled to cell numbers, according to a linear relationship between MTT response and cell number, using each corresponding $\mathrm{IC}_{50}$ and Table 1 shows the different concentrations used.(43-45)

Table 1: $\mathrm{IC}_{50}$ determined by the MTT and corresponding dose used for $10^{4}$ cells.

\begin{tabular}{|l|l|l|l|}
\hline Exposure time $(\mathrm{hrs})$ & $0-24$ & 48 & 72 \\
\hline $\mathrm{IC}_{50}(\mu \mathrm{M})$ & $0.55 \pm 0.16$ & $0.31 \pm 0.05$ & $0.27 \pm 0.02$ \\
\hline DOX Concentration $(\mu \mathrm{M})$ & 13.75 & 77.5 & 135 \\
\hline
\end{tabular}




\subsection{Confocal Laser Scanning Fluorescence Microscopy:}

Confocal Laser Scanning Fluorescence Microscopy (CLSM) was employed to visualise and confirm the DOX intracellular internalisation and subcellular localisation. Figure 2 illustrates the images for different DOX exposure times, from $2 \mathrm{hrs}$ to $72 \mathrm{hrs}$; clearly demonstrating that DOX is predominantly accumulated in the nuclear region at all time points. The DOX nuclear accumulation is obvious even after only 2hrs, suggesting that this commercial drug is trafficked straight to the nuclear area without any accumulation in the cytoplasm up to $24 \mathrm{hrs}$. Some trace amounts do appear in the cytoplasm at 48 and $72 \mathrm{hrs}$, consistent with the onset of a late cytoplasmic DOX mechanism of action associated with oxidative stress as a result of reactive oxygen species production.(12) Compared to healthy control cells, exposed cells appear smaller in size and round or oval in shape and exhibit noticeable fragmentation of nucleoli within the nucleus, with tightly packed cytoplasm and membrane blebbing. All these morphological changes confirm that cells are undergoing apoptosis. $(16,18,29,46)$

1.
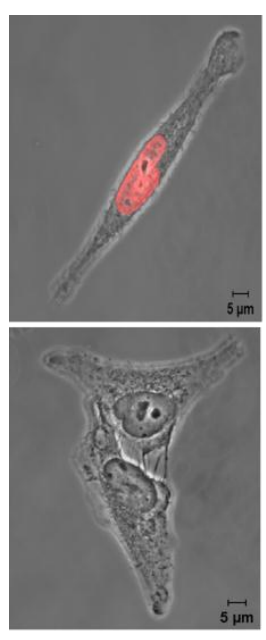

2.
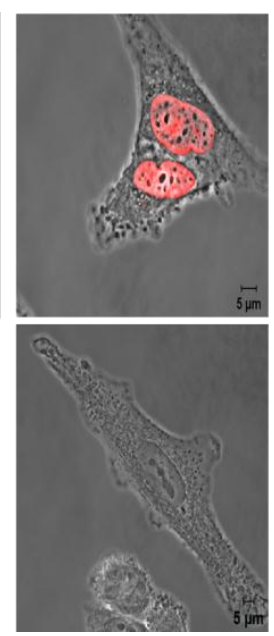

3.
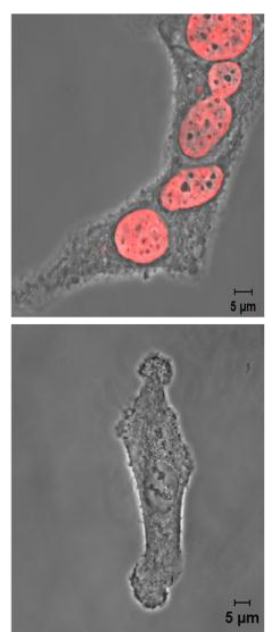

4.
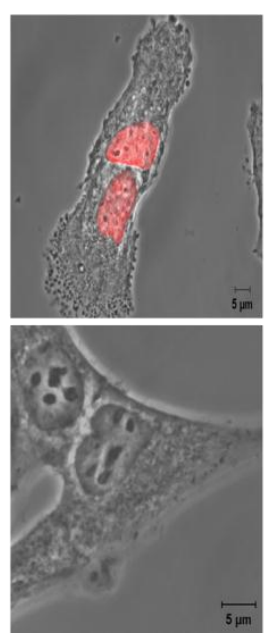

5.
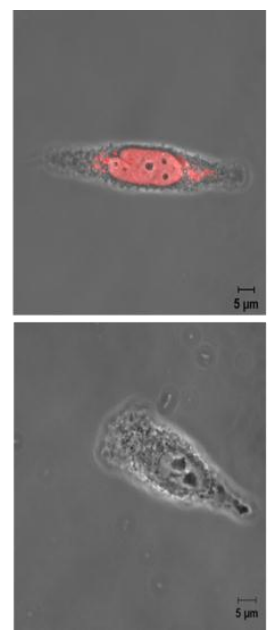

6.
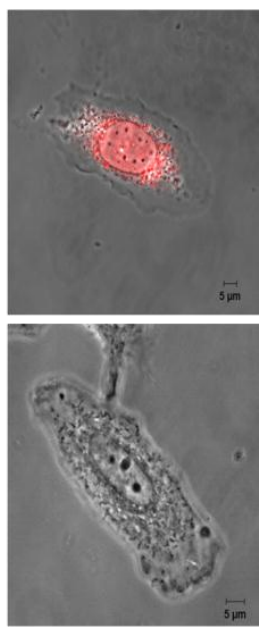

Figure 2: Confocal Laser Scanning Fluorescence images of A549 cells after DOX exposure and corresponding controls: 1.2hrs DOX exposure, 2.6hrs DOX exposure, 3.12hrs DOX exposure, 4.24hrs DOX exposure, 5.48hrs DOX exposure and 6.72hrs DOX exposure 


\subsection{Raman micro spectroscopy:}

Raman micro spectrosopy has previously been demonstrated to be cabable of tracking DOX inside the cellular compartments and differentiating between its different mechanisms of action and the cellular responses due to drug treatment at a fixed timepoint of $24 \mathrm{hrs}$ exposure. In order to further investigate the subcellular responses and to track the drug pathway, Raman profiles from the three subcellular compartments, nucleolus, nucleus and cytoplasm, were analysed at shorter timescales of 2,6 and $12 \mathrm{hrs}$ at the $24 \mathrm{hr} \mathrm{IC}_{50}$ concentration, and at the longer exposure times of $48 \mathrm{hrs}$ and $72 \mathrm{hrs}$, at the $\mathrm{IC}_{50}$ concentration, adjusted to the cell number, of these time points, as determined using the MTT assay (Figure 1, Table 1).

A.

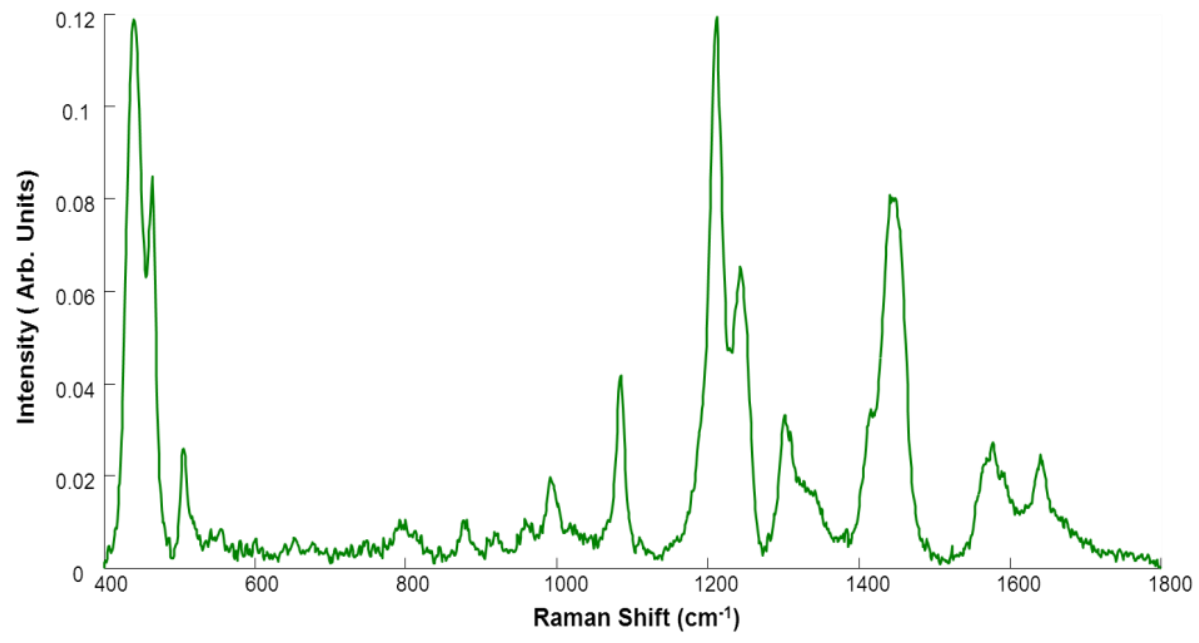

B.

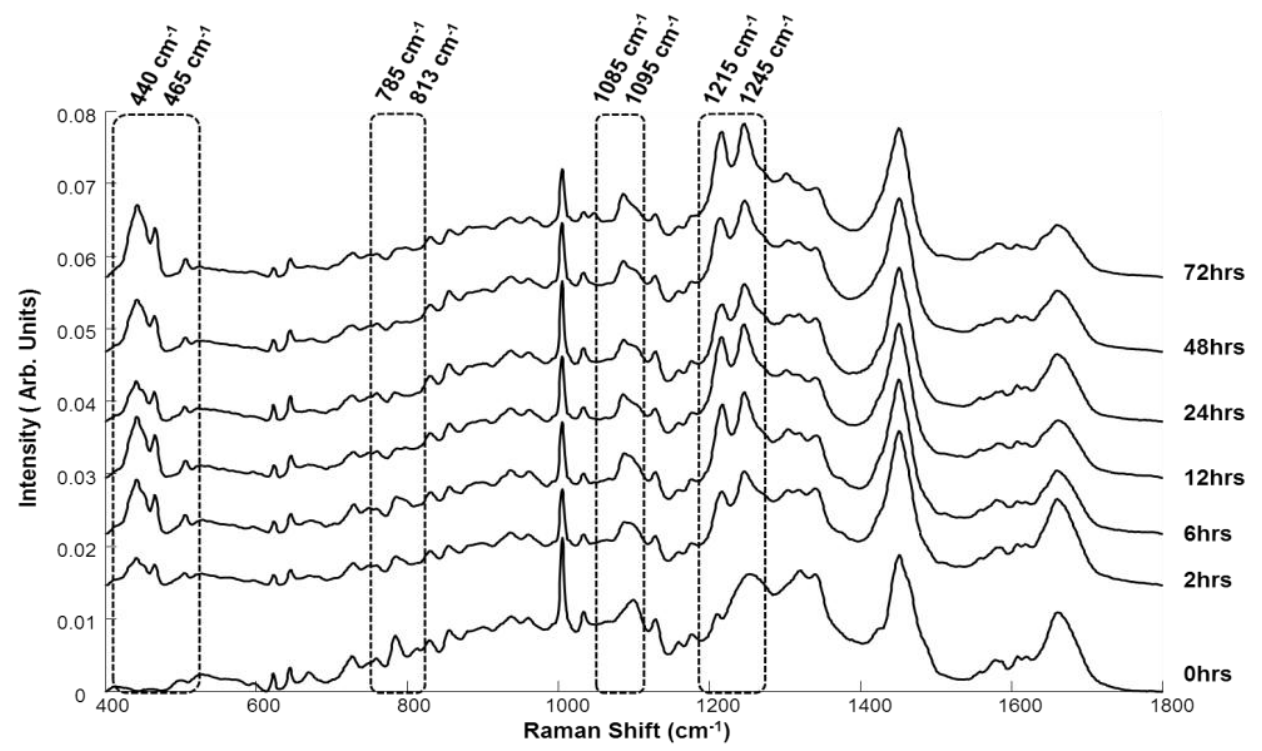


C.

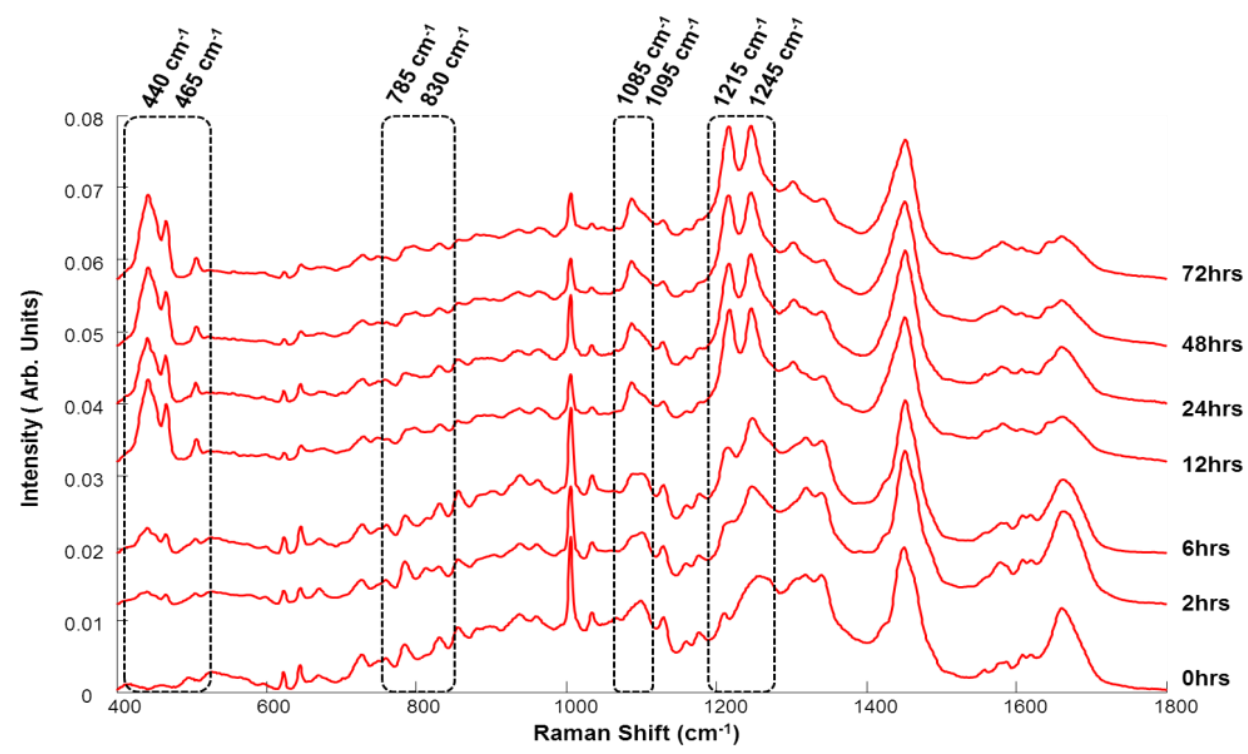

D.

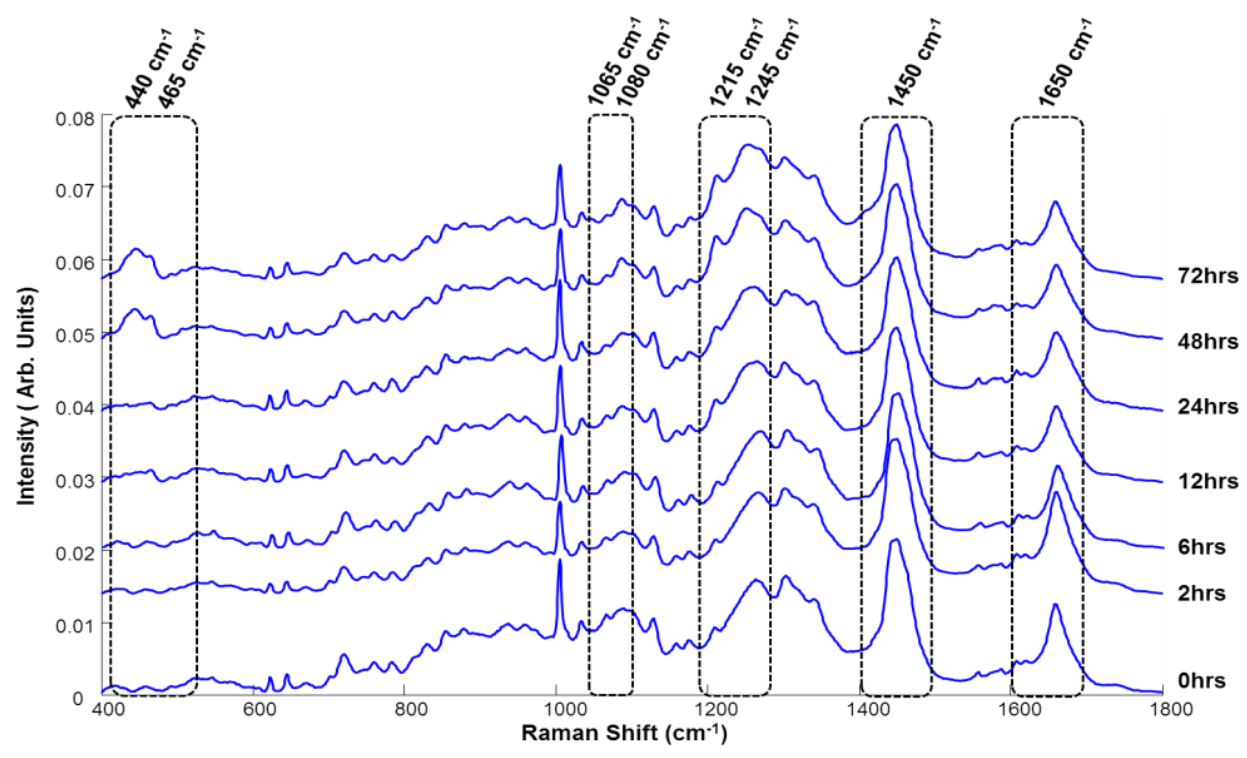

Figure 3: Raman spectra after background subtraction, baseline correction and vectornormalisation of A. Doxorubicin dissolved in sterile water and mean spectra of A549 cell line for $0,2,6,12,24,48$ and 72hrs of B. nucleolus C. nucleus and D. cytoplasm

Figure 3 shows the mean spectra for each time point of the three cellular localisations, namely the nucleus, the primary location of DNA, the nucleolus, a sub-compartment of the nucleus, which contains RNA and small amount of DNA, and the surrounding cytoplasm 
containing the cytoskeleton, a framework of protein filaments, all protected by the plasma membrane. $(47,48)$

In general, nucleic acids can be identified by peaks characteristic of nucleotide and sugarphosphate backbone vibrations (24) and the main bands are for example at $785 \mathrm{~cm}^{-1}$, assigned to cytosine and thymine (DNA/RNA) and DNA backbone O-P-O stretching, $813 \mathrm{~cm}^{-1}$, related to RNA O-P-O stretching, $830 \mathrm{~cm}^{-1}$, corresponding to DNA B form O-P-O asymetric stretching and $1095 \mathrm{~cm}^{-1}$, assigned to DNA $\mathrm{PO}_{2}{ }^{-}$symmetric stretching. Protein signatures are dominated by peaks related to Amide III and Amide I vibrations, between $1230-1280 \mathrm{~cm}^{-1}$ and 1640-1695 $\mathrm{cm}^{-1}$, respectively, and amino acids containing phenyl groups, such as phenylalanine peaks at for example 1005 and $1030 \mathrm{~cm}^{-1}$, tryptophan at $760 \mathrm{~cm}^{-1}$ and tyrosine at 645,853 and $877 \mathrm{~cm}^{-1}$. Lipids are predominatly represented by peaks at $700-720 \mathrm{~cm}^{-1}$, related to $\mathrm{C}-\mathrm{C}-\mathrm{N}+$ symmetric stretching in phosphatidylcholine, $1303 \mathrm{~cm}^{-1}$ assigned to $\mathrm{C}-\mathrm{H}$ vibration and between 1410 and $1495 \mathrm{~cm}^{-1}$ corresponding to $\mathrm{C}-\mathrm{H}$ deformation. $(24,29,49)$

Since the Raman spectra are characteristic of the molecular structure, any changes to that structure, for example after chemotherapeutic treatment, can be detected and monitored.

As an illustration, for both nucleolar and nuclear regions (Figure 3B and C), an obvious shift towards lower wavenumbers of the band at $1095 \mathrm{~cm}^{-1}$ confirms again that DOX is able to bind to DNA externally, starting from the early stages of exposure (29), and a decrease of the band at $785 \mathrm{~cm}^{-1}$ indicates a progressive DNA/RNA denaturation, while in the nuclear region, there is a decrease in the features at $830 \mathrm{~cm}^{-1}$ and, in the nucleolar area, an almost complete disappearance of the band at $813 \mathrm{~cm}^{-1}$, potentially due to cessation of DNA replication as a consequence of DNA denaturation and fragmentation. $(50,51)$ In the cytoplasmic area (Figure 3D), a slight increase in features at 1065 and $1080 \mathrm{~cm}^{-1}$ is observed, corresponding to protein $\mathrm{C}-\mathrm{N}$ stretching, which may correspond to an increase of signaling proteins in cells going under apoptosis.

It is notable that, for all cellular regions and over the time course, there is an increase in the principle DOX features (Figure 3A, indicated by the highlighted regions in Figure $3 \mathrm{~B}, \mathrm{C}$ and D) at 440 and $465 \mathrm{~cm}^{-1}$, respectively corresponding to $\mathrm{C}-\mathrm{C}-\mathrm{O}$ and $\mathrm{C}-\mathrm{O}$ vibrations, and at 1215 and $1245 \mathrm{~cm}^{-1}$, related to $\mathrm{C}-\mathrm{O}-\mathrm{H}$ and $\mathrm{C}-\mathrm{O}$. Notice, however, that DOX features only appear in the cytoplasm starting from $48 \mathrm{hrs}$ exposure. Similar observations were found in CLSM images (Figure 2), confirming the primary localisation of DOX in the combined nuclear area for all time points before $48 \mathrm{hrs}$ treatment.

In order to examine further the DOX cellular pathway, PCA of exposed cells versus control was employed and a clear separation occured according to PC1 for all time points compared 
to control, as previously demonstrated for $24 \mathrm{hr}$ exposure (29) (data not shown). The evolution of DOX peak intensities at 440, 465, 1215 and $1245 \mathrm{~cm}^{-1}$, corresponding respectively to $\mathrm{C}-\mathrm{C}-\mathrm{O}, \mathrm{C}-\mathrm{O}, \mathrm{C}-\mathrm{O}-\mathrm{H}$ and $\mathrm{C}-\mathrm{O}$ vibrations of the DOX molecule, in the loading of PC1 was analysed, as shown in Figure 4. The intensity is expressed as a percentage of the highest value of each respective band in the three subcellular regions.
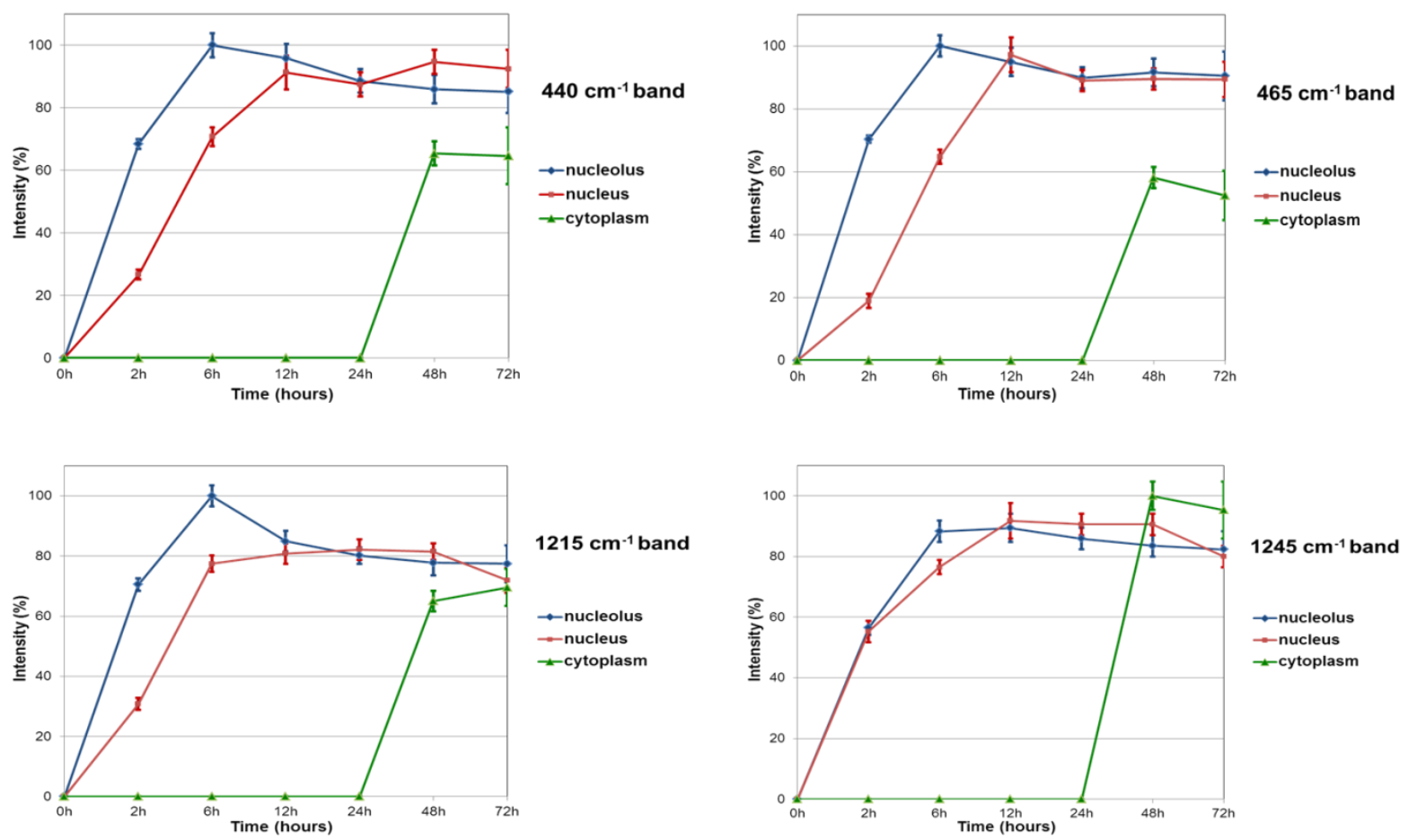

Figure 4: Evolution of DOX Raman bands at 440, 465, 1215 and $1245 \mathrm{~cm}^{-1}$ as a function of time for the A549 cell line for each cellular compartment, nucleolus, nucleus and cytoplasm. Intensities are expressed in percentage according to the maximum value for each band over the three cellular compartments and standard deviation corresponds to the spectral variations of each band.

It is obvious that there is a progressive increase of DOX intracellular concentration until a plateau is reached after 6-12hrs exposure and DOX is seen to accumulate in the nucleolus first, then the nucleus and after 48hrs appears in the cytoplasm. Since the bands at 1215 and $1245 \mathrm{~cm}-1$ can be influenced by the proximity of protein features, further analysis was focused on the two bands at 440 and $465 \mathrm{~cm}-1$. Notably, according to these two DOX Raman bands, there is more DOX in the nucleolus than the nucleus for 2, 6 and $12 \mathrm{hrs}$ exposure, with a maximum at $6 \mathrm{hrs}$. These observations are consistent with a mechanism of DOX being trafficked straight to the combined nuclear area, after a passive diffusion to the cells due to its 
high lipophilicity, binds to proteasomal then translocates into the nuclear area,via nuclear pores, where it dissociates from the proteasome complex and binds to DNA with hight affinity, $(1,7)$ a larger amount accumulating in the denser nucleolar area, which saturates more rapidly. Accumulation in the cytoplasm is only evident after $48 \mathrm{hrs}$, confirming previous studies showing that the intracellular DOX is primarily accumulated in the nuclear area, at short exposure times, and that the main mechanism of action is one of DNA intercalation, interfering with both DNA and RNA polymerase and as a consequence inducing DNA replication and RNA transcription blockage. $(7,52)$ The observed plateau in the nuclear and nucleolar regions is more notable, given that the doses for 48 and $72 \mathrm{hrs}$ were increased to the respective doses of $77.5 \mu \mathrm{M}$ and $135 \mu \mathrm{M}$, respectively, compared to $13.75 \mu \mathrm{M}$ for $24 \mathrm{hrs}$ (Table 1). Nevertheless, it is clear that the DOX concentration inside the combined nuclear regions becomes approximately constant after $\sim 24 \mathrm{hrs}$ exposure, after which DOX begins to accumulate in the cytoplasm due to nuclear membrane loss of integrity. $(46,53)$

The behaviour is consistent with saturation of nuclear binding sites after a certain time and any additional drug taken up by cells accumulates in the cytoplasm. $(54,55)$

In order to track the cellular changes associated with the progressive uptake of DOX in the subcellular regions, PLSR was employed, and spectra were regressed against time, progressively increasing the time interval from $0-6$ to $0-72 \mathrm{hrs}$. The resultant regression coefficients for the nucleolar and nuclear region are shown in Figure 5.

In the case of the regression as a function of time for the nuclear region (Figure 5B), the coefficients over the period 0-6hrs and 0-12hrs are almost identical, whereas regression beyond this period results in significant changes to the regression co-efficients. In the case of the nucleolar spectral data (Figure 5A), such significant changes in the regression co-efficients are evident on progressing from $0-6 \mathrm{hrs}$ to $0-12 \mathrm{hrs}$, and beyond. For both cellular regions, the time points after which the regression co-efficients begin to change significantly co-incide with those of the onset of saturation of the DOX related spectral features in Figure 4, indicating that the regression over the timepoints up to saturation identifies spectral features associated with the initial drug mechanism of action, before saturation, after which the cellular responses become evident. 
A.

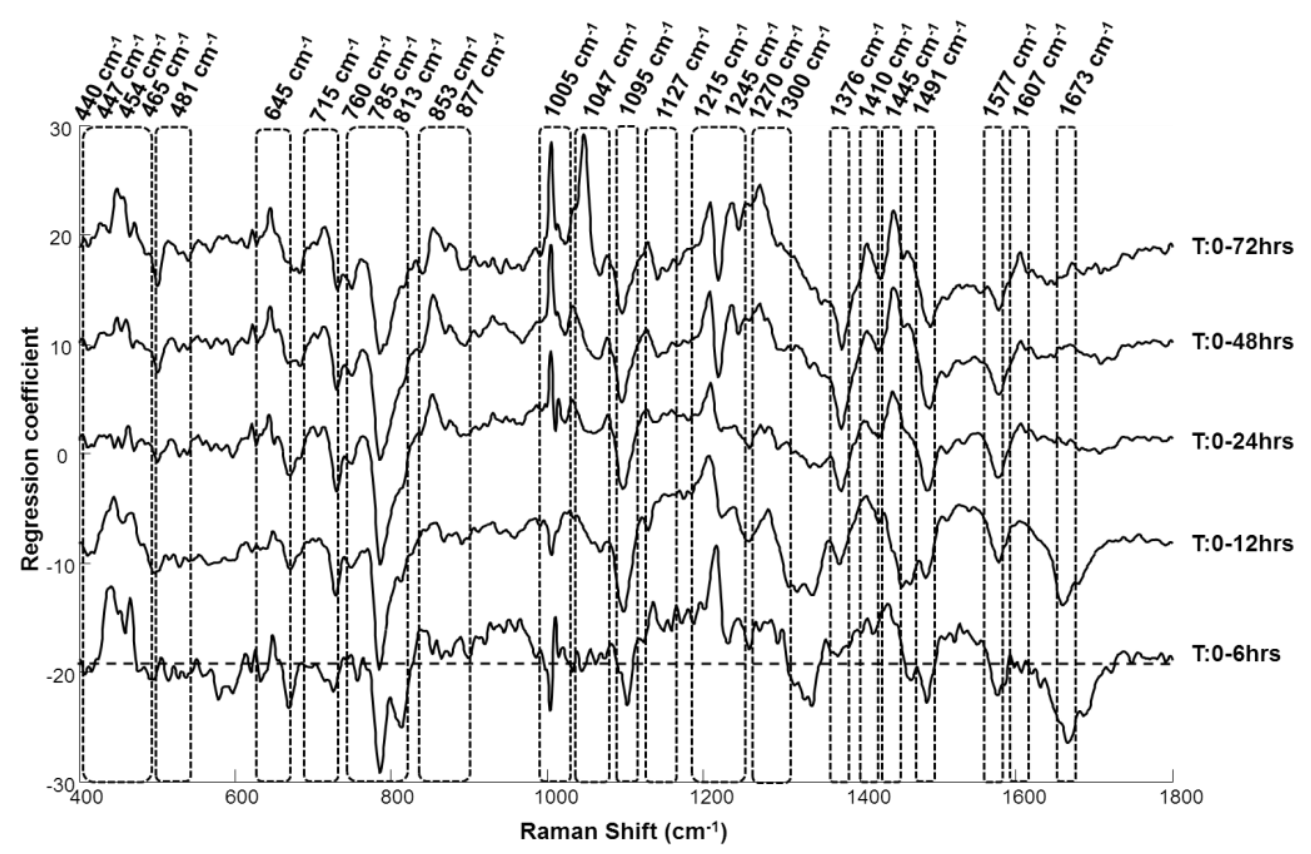

B.

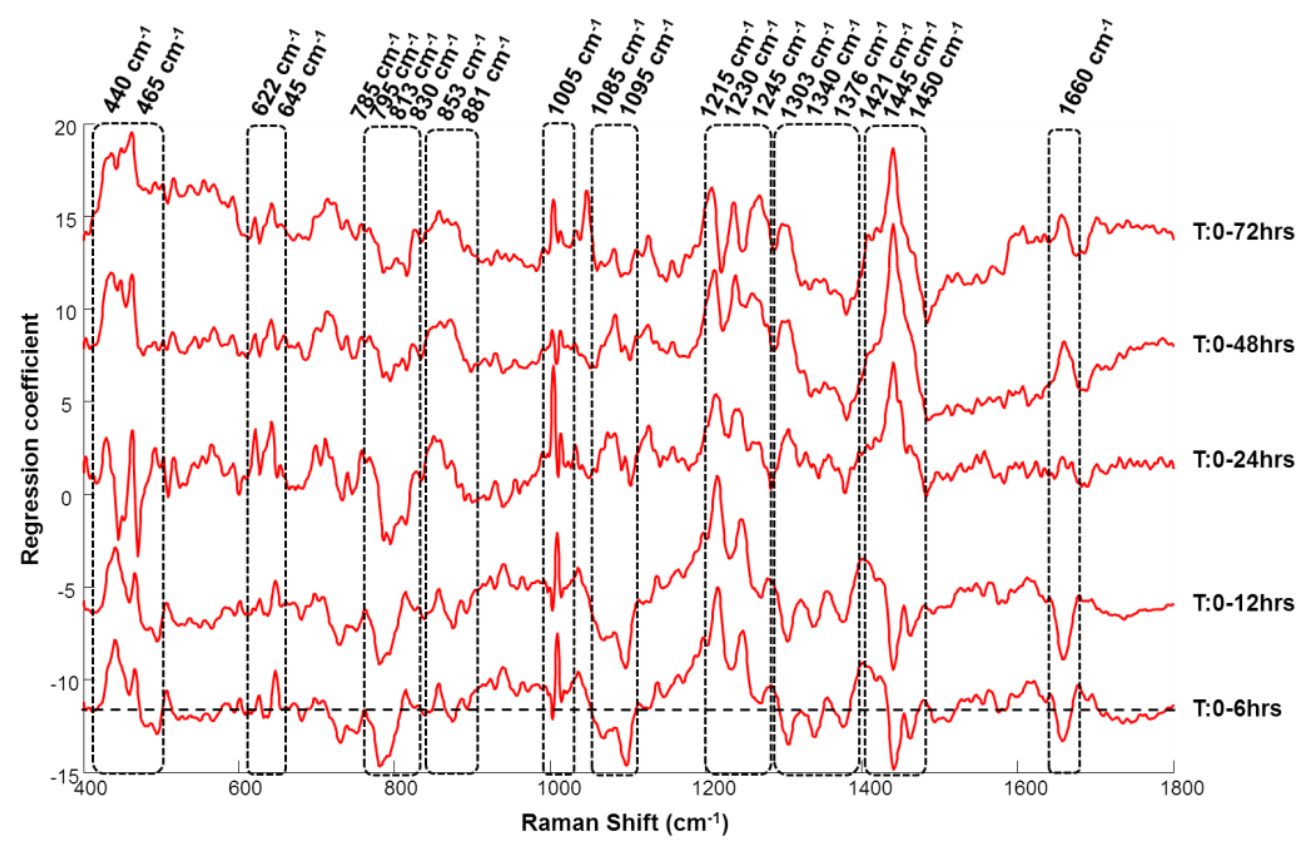

Figure 5: Regression coefficients obtained by PLSR analysis as a function of time over progressive exposure time intervals $(\mathrm{T})$ for $\mathbf{A}$. nucleolus and B. nucleus. The dashed horizontal line indicates the zero-point for T: 0-6hrs and the other co-efficients are off set for clarity. 
In the T:0-6hrs regression co-efficients for the nucleolar region (Figure 5B), notable positive DOX features are observed at 440-465 $\mathrm{cm}^{-1}$ and $1215-1245 \mathrm{~cm}^{-1}$, indicating the progressive accumulation of DOX, as shown in Figure 4. A concomittent decrease in cellular features corresponding to nucleic acids is observed, at $785 \mathrm{~cm}^{-1}$ (cytosine and thymine, DNA backbone O-P-O stretching), $813 \mathrm{~cm}^{-1}$ (RNA O-P-O strecthing), $853 \mathrm{~cm}^{-1}$ (tyrosine ring breathing), $1095 \mathrm{~cm}^{-1}$ (DNA backbone O-P-O stretching), $1270 \mathrm{~cm}^{-1}$ (RNA uracil and cytosine ring stretching), $1300 \mathrm{~cm}^{-1}$ (RNA cytosine and adenine ring stretching), $1376 \mathrm{~cm}^{-1}$ (thymine), and $1577 \mathrm{~cm}^{-1}$ (adenine and guanine),representing a modification of their cellular content due to blockage of DNA replication and transcription as a result of DOX treatment,as well as a change in the profile of peaks at 1410,1445 and $1491 \mathrm{~cm}^{-1}$, indicating lipid denaturation, probably of the surronding cytoplasmic membrane and features at $1005 \mathrm{~cm}^{-1}$ (phenylalanine), $1607 \mathrm{~cm}^{-1}$ (tyrosine and phenylalanine ring vibration $\mathrm{C}=\mathrm{C}$ ) and $1673 \mathrm{~cm}^{-1}$ (Amide I), indicating a change in nucleolar proteins.(21, 24, 29, 49, 51, 56, 57)

Over the regression period $\mathrm{T}: 0-12 \mathrm{hrs}$, although the overall profile of the co-efficients is distinct compared to that of the nucleolar region, similar spectral changes are observed for the nuclear region, in addition to those at $830 \mathrm{~cm}^{-1}$ (O-P-O asymmetric stretching, DNA B form), $881 \mathrm{~cm}^{-1}$ (Deoxyribose ring breathing) and $1340 \mathrm{~cm}^{-1}$ (adenine and guanine).

The nucleolar and nuclear region are composed of similar biochemical constituents, and similar changes to these are prominent in the regression co-efficients of both regions. However, the distinctly different profiles in Figure 5A (Nucleolus T:0-6hrs) and Figure 5B (Nucleus 0-12hrs) indicate different rates and degrees of interactions with the constituent conponents in the different subcellular regions.

Notably, as shown in Figure S2, for each cellular region, the co-efficients for regression against the internalised dose, as determined by the peak intensity in the loading 1 of PCA control versus exposed cells (Figure 4), are largely invariable, and almost identical to the time dependent regression co-efficient profile (T:0-6hrs for nucleolus and T:0-12 for nucleus) (Figure 5) up to the saturation point (Figure 4)

So, for both nucleus and nucleolus and for both regression against short time exposure and DOX cellular concentration, a notable decrease in DNA and RNA features for example at $728,785-795,813,1376$ and $1486 \mathrm{~cm}^{-1}$ is evident. However, the changes to the nucleic acid features over this initial period are much more pronounced and more rapid in the nucleolar region than in the nucleus itself.

Following the initial DOX binding interactions in the nucleoli and then nuclear regions of the cell, and although the DOX concentrations saturate in the nuclear regions after $\sim 12 \mathrm{hrs,}$ 
(Figure 5), the cellular features continue to evolve as a function of time, in response to the action of the drug. This can be clearly seen in Figure 5, but, in order to differentiate the spectral characteristics of the initial chemical interactions of the drug from the subsequent cellular responses, the spectral evolution over the time period 24-72hrs was regressed against time and internalised cellular DOX concentration. Notably, in the PLSR analysis of nucleolus and nucleus regressed against time over the later stages, shown in Figure 6 (IA and IIA), only cellular features appear and no DOX features are apparent, which confirms the fact that after certain time, DOX reaches a constant concentration inside the nuclear regions of the cells, as evidenced by the plateau in Figure 4.

As seen in Figure 6I, for the nucleolar regions at late stages (24, 48 and $72 \mathrm{hrs})$, there is an increase in protein features at 447, 454, $1005 \mathrm{~cm}^{-1}$ (phenylalanine), $853 \mathrm{~cm}^{-1}$ (tyrosine ring breathing), $1207 \mathrm{~cm}^{-1}$ (phenylalanine, tryptophan and tyrosine), $1230 \mathrm{~cm}^{-1}$ (Amide III), and $1660 \mathrm{~cm}^{-1}$ (Amide I), consistent with an afflux of anti-apoptotic protein trying to repair DNA and avoid apoptosis.(12) There is also a significant decrease in DNA features at $785 \mathrm{~cm}^{-1}$ (cytosine and thymine), $830 \mathrm{~cm}^{-1}$ (DNA B form), $1220 \mathrm{~cm}^{-1}$ (adenine and thymine) and 1577 $\mathrm{cm}^{-1}$ (adenine and guanine), representative of DNA depletion and denaturation due to a long term effects of DOX.

Similar increases in protein features as a function of time in the later stages of exposure is apparent in the nuclear area, as shown in Figure 6 II, in addition to a progressive decrease in DNA features at 785, $795 \mathrm{~cm}^{-1}$ (cytosine and thymine), $1095 \mathrm{~cm}^{-1}$ (DNA backbone O-P-O symmetric stretching), $1220 \mathrm{~cm}^{-1}$ (adenine and thymine), $1376 \mathrm{~cm}^{-1}$ (thymine), $1577 \mathrm{~cm}^{-1}$ (adenine and guanine), and a lipid denaturation indicated by peaks at 700-715-720, 1127 and 1450 and $1491 \mathrm{~cm}^{-1}$. 
I.

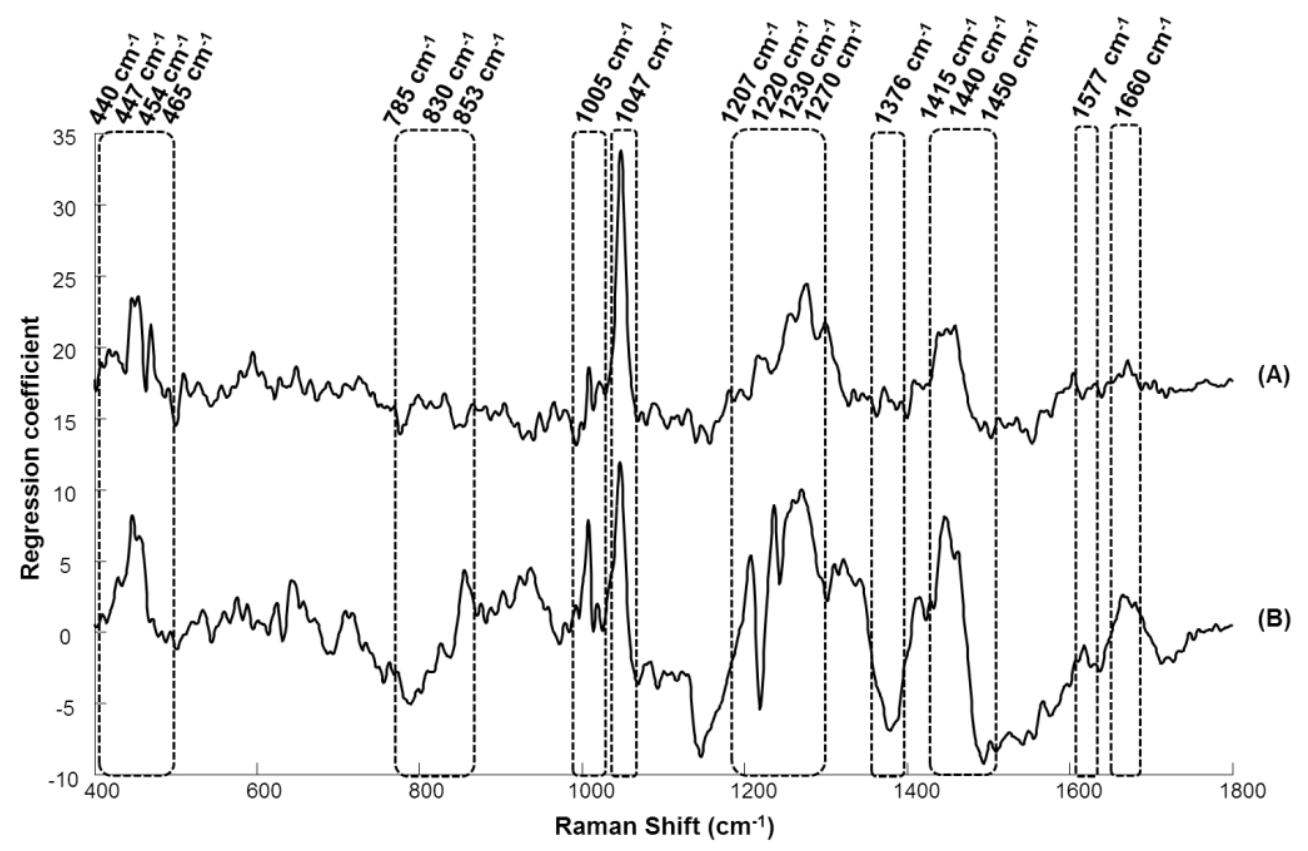

II.

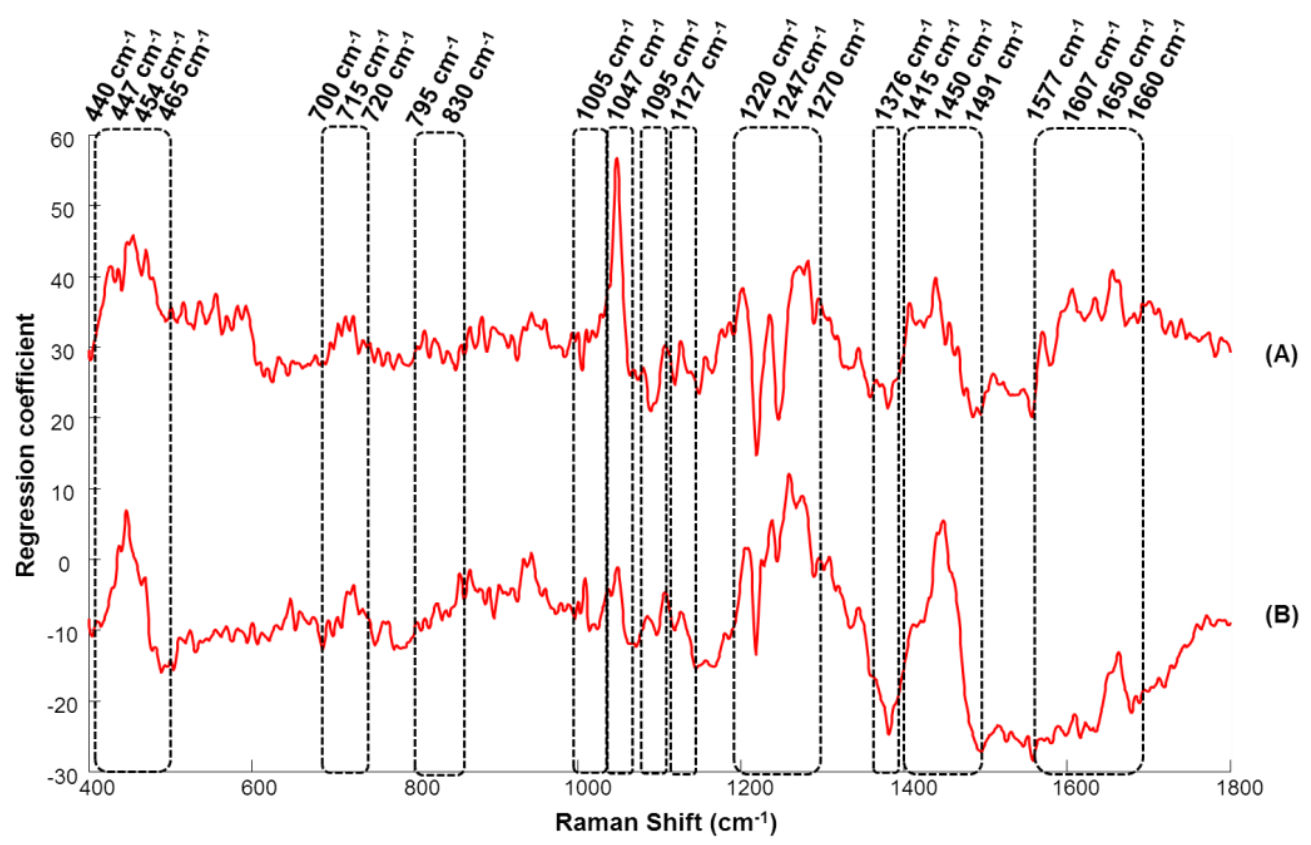

Figure 6: Regression coefficients obtained by PLSR analysis of long term DOX exposure over the time period (24-72 hours) of I.nucleolus and II. nucleus (A) regressed against time and (B) against DOX concentration inside cells determined by the peaks intensities of the band at $465 \mathrm{~cm}^{-1}$ in loading 1 of PCA exposed cells versus control. 
In both nucleolar and nuclear regions at prolonged exposures, a notable increase is observed in features at $1047 \mathrm{~cm}^{-1}$ (RNA P-O stretching, sugar phosphate $-\mathrm{C}-\mathrm{O}-$-stretching), and 1270 $\mathrm{cm}^{-1}$ (RNA Uracil and Cytosine ring stretching), while that at $1376 \mathrm{~cm}^{-1}$ (thymine) is seen to decrease. The continued changes to RNA features in both nucleolus and nucleus over the later time period could be explained by a decrease of RNA as a consequence of DNA denaturation and blockage of its replication but the concomitant increase in some RNA peaks could be due to nucleolar fragmentation, resulting in RNA spread into the nucleus. $(16,58)$

In addition to spectral features which may be characteristic of DNA and RNA depletion and nucleolar fragmentation, there is an increase in both lipid and protein features, at $645 \mathrm{~cm}^{-1}(\mathrm{C}$ C tyrosine), $715 \mathrm{~cm}^{-1}$ (choline), $720 \mathrm{~cm}^{-1} \quad(\mathrm{C}-\mathrm{C}-\mathrm{N}+$ symmetric stretching inphosphatidylcholine), $760 \mathrm{~cm}^{-1}$ (tryptophan ring breathing), 853-877 $\mathrm{cm}^{-1}$ (tyrosine ring breathing), $1005 \mathrm{~cm}^{-1}$ (phenylalanine), $1127 \mathrm{~cm}^{-1}$ (C-N stretching), 1410-1445 cm ${ }^{-1}\left(\mathrm{CH}_{2}\right.$ vibrations), $1607 \mathrm{~cm}^{-1}$ (tyrosine and phenylalanine ring vibration $\mathrm{C}=\mathrm{C}$ ), and $1656-1673 \mathrm{~cm}^{-1}$ (Amide I) (Figure 5 and 7), as a cellular response to DOX exposure, which may be associated with the efflux of anti-apoptotic protein and a synthesis of lipidic vesicules as a way to remove DOX to the extracellular environment. $(29,56,59,60)$

The increase in phenylalanine in both nucleolar and nuclear regions seems to be a marker of the late apoptosis stage, at which point nucleolar fragmentation is complete, leaving an empty space with only cellular membrane (Figure 6).(57, 61)

Thus, it appears that regression against DOX cellular concentration shows the initial DOX accumulation inside the cells, its nuclear binding and its subsequent effects, including DNA damage, while regression against varying time intervals can elucidate and differentiate both the initial DOX mechanism of action and its cellular effects, such as depletion in DNA, RNA and proteins leading to apoptosis and the cells reactions to those DOX effects which could be a marker of any cellular-drug resistance. 


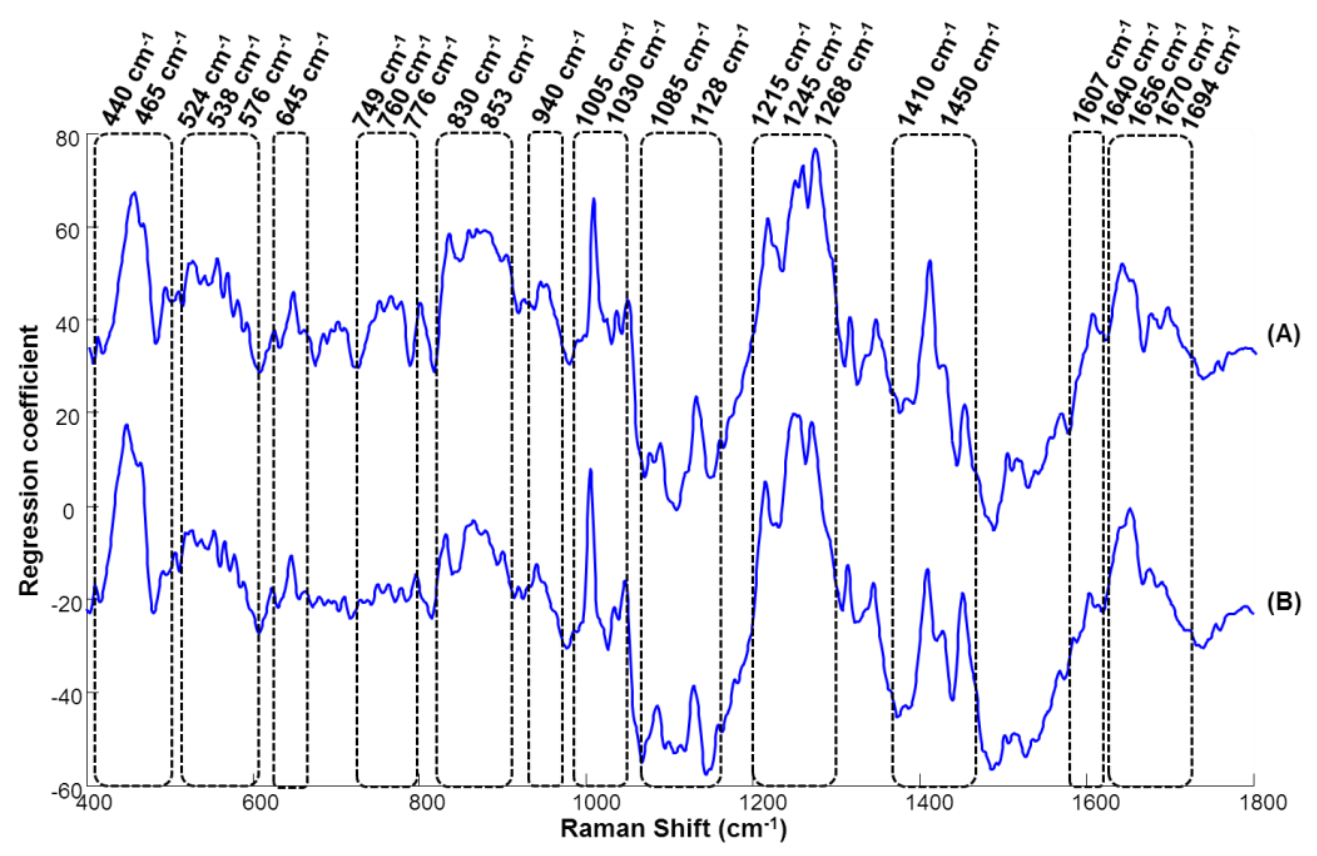

Figure 7: Regression coefficients obtained by PLSR analysis of cytoplasm (A) regressed against time full range and (B) against DOX concentration inside cells determined by peaks intensities of band at $465 \mathrm{~cm}^{-1}$ in loading 1 of PCA exposed cells versus control

Figure 7 shows the PLSR of the cytoplasmic region of the cell against time and DOX cellular concentration. In both regression co-efficient profiles, there are obvious DOX features at 440$465 \mathrm{~cm}^{-1}$ and $1215-1245 \mathrm{~cm}^{-1}$, in addition to cellular ones related to proteins and lipids, for example at $524 \mathrm{~cm}^{-1}$, corresponding to phosphatidylserine externalization as an indicator of cell signalling in apoptosis $(62,63), 538 \mathrm{~cm}^{-1}$ related to cholesterol ester, which increases due to alteration of the function of integral endoplasmic reticulum membrane proteins and is a marker of apoptosis $(64,65), 576-776 \mathrm{~cm}^{-1}$ (phosphatidylinositol) related to membrane trafficking, 645-830-853 $\mathrm{cm}^{-1}$ (tyrosine), 749-760 $\mathrm{cm}^{-1}$ (tryptophan), $940 \mathrm{~cm}^{-1}$ (C-C stretching of protein), 1085 and $1128 \mathrm{~cm}^{-1}$ (C-N stretch), $1268 \mathrm{~cm}^{-1}$ (Amide III), $1410-1450 \mathrm{~cm}^{-1}\left(\mathrm{CH}_{2}\right.$ deformation), $1607 \mathrm{~cm}^{-1}\left(\mathrm{C}=\mathrm{C}\right.$ phenylalanine and tyrosine), $1640-1694 \mathrm{~cm}^{-1}$ (Amide I of different conformational forms indicating a protein denaturation). $(56,59)$ Features at 645 $1005 \mathrm{~cm}^{-1}$ (C-C phenylalanine) and $1030 \mathrm{~cm}^{-1}(\mathrm{C}-\mathrm{H}$ phenylalanine $)$ indicate a change in the protein environment due to DOX exposure (50), while changes in the profile of the band at $1450 \mathrm{~cm}^{-1}$ (C-H deformation) and around $1303 \mathrm{~cm}^{-1}$ (lipid C-H vibration) (59) are consistent with a lipid structure denaturation by peroxidation due to ROS production under DOX treatment. (13) 


\section{Discussion:}

Raman spectroscopic microscopy can clearly track the kinetics of the uptake and accumulation of the chemotherapeutic drug DOX at a subcellular level in vitro, and can differentiate the biochemical responses associated with the subcellular regions of nucleolus, nucleus and cytoplasm, both in terms of the mechanisms of action, and the subsequent cellular metabolic responses. In both cases, the spectroscopic signatures are a complex combination of the contibutions of the many biomolecular responses and their evolution requires the use of multivariate regression analysis. Independent Components Analysis can be used to extract the primary contributions of this combinatorial response, at each timepoint, as shown in Figure S3, for each exposure timepoint for (A) nucleolar and (B) nuclear regions of the cell, again highlighting the multivariate nature of the spectral responses.

The evolution of selected features can be plotted against time, and correlated with that of the uptake and accumulation of the DOX in the different subcellular regions, as well as each others, as shown in Figure 8. The intensities of DNA, RNA, proteins and lipids bands was determined by ICA after DOX subtraction, as ICA can identify spectral cellular components contributions independently while DOX band was determined by PCA control vs exposed cells (Figure 4).

The interaction with DNA and RNA in both the nucleolar and nuclear regions of the cell as a function of time is apparent in Figure 8A, showing the evolution of DNA features at $830 \mathrm{~cm}^{-1}$ (O-P-O asymmetric stretching, DNA B form) and $881 \mathrm{~cm}^{-1}$ (Deoxyribose ring breathing) and RNA features at $1270 \mathrm{~cm}^{-1}$ (RNA Uracil and Cytosine ring stretching) and $1300 \mathrm{~cm}^{-1}$ (RNA Cytosine and Adenine ring stretching). Notably, the feature at $785 \mathrm{~cm}^{-1}$ (Cytosine and Thymine, DNA backbone O-P-O stretching), can be ascribed to either DNA or RNA. 
A. (i)

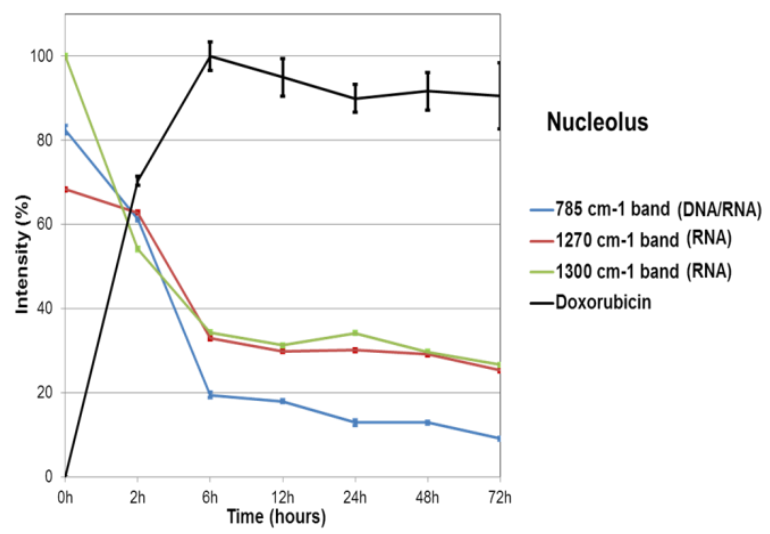

B. (i)

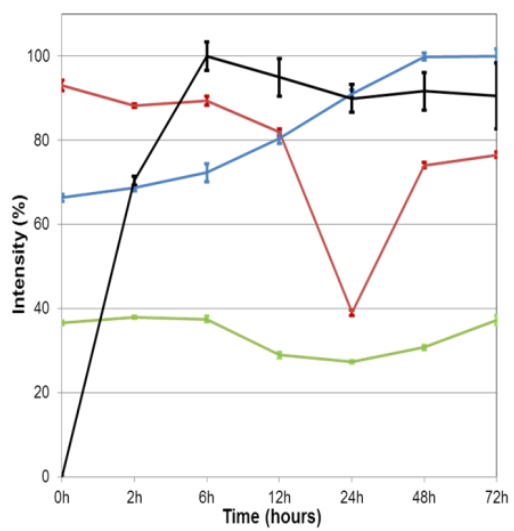

(ii)

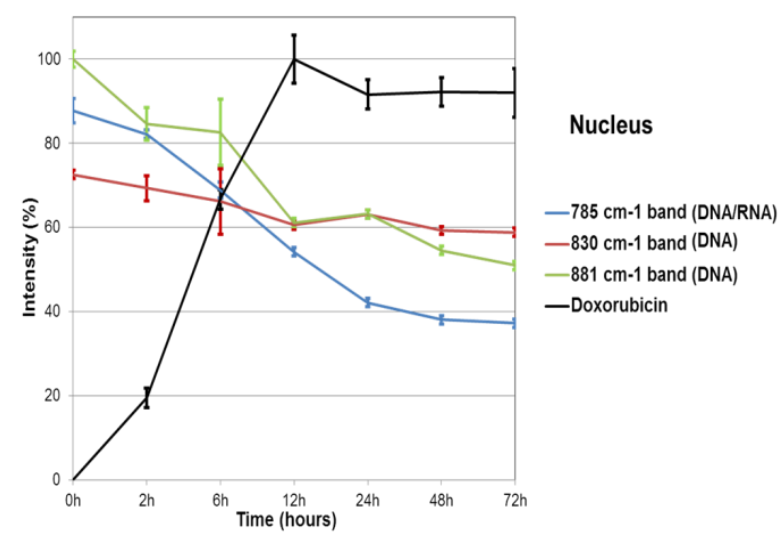

(ii)

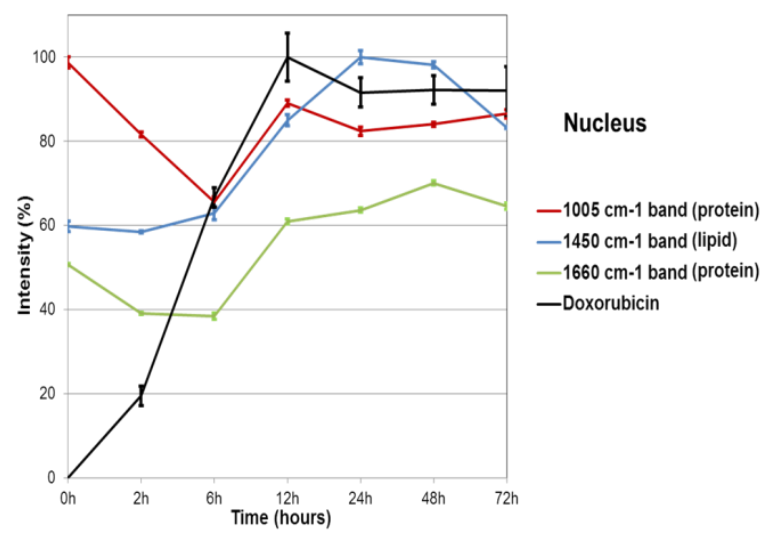

Figure 8: A. Evolution of DOX $\left(465 \mathrm{~cm}^{-1}\right)$ and selected RNA $\left(785,1270,1300 \mathrm{~cm}^{-1}\right)$ and DNA $\left(785,830,881 \mathrm{~cm}^{-1}\right)$ Raman bands as a function of time for the A549 cell line for each nuclear cellular compartment, (i) nucleolus and (ii) nucleus. B. Evolution of DOX $\left(465 \mathrm{~cm}^{-1}\right)$ and selected protein $\left(1005,1230,1660 \mathrm{~cm}^{-1}\right)$, lipid $\left(1450 \mathrm{~cm}^{-1}\right)$ Raman bands as a function of time for the A549 cell line for each nuclear cellular compartment, (i) nucleolus and (ii) nucleus. Intensities are expressed in percentage according to the maximum value for each nuclear area and standard deviation corresponds to the spectra variations for each band.

The changes in the nucleic acid bands in the nucleolar region are concomitant with the accumulation of DOX, and the changes cease when the accumulation of DOX saturates, associating these with an instantaneous interaction with the biochemical components, and therefore the initial DOX-DNA binding. $(66,67)$ In the nucleus, the equivalent changes occur more slowly, but also appear to saturate once the accumulation of DOX in the nucleus has saturated. A further observation is that the relative changes in the nucleic acid spectral features are much stronger in the nucleolus than in the nuclear region. Moreover, the same 
kinetics of evolution were found using PLSR, highlighting that the same cellular features, mainly DNA and RNA are affected by DOX in both nucleolus and nucleus, due to interuption of DNA replication and RNA transcription, but at different rates and intervals. DOX affects the nucleolus instantaneously, and once saturation of DOX is reached at 6hrs, an almost total reduction of DNA and RNA features to $20 \%$ has occured. In the case of the nucleus, this decrease is slower even after saturation at $12 \mathrm{hrs}$ and reaches only $\sim 40 \%$ of the initial levels. It is also obvious that, after DOX exposure, proteins and lipids (Figure $8 \mathrm{~B}$ ) start decreasing as a consequence of RNA/DNA alteration, and then increase at later stages of the cellular responses, which corresponds to an increase of anti-apoptotic proteins and a synthesis of lipids vesicules as a cellular reaction to the chemotherapeutic treatment, after which, cells initiate late apoptosis corresponding to a point of no return.

Previous studies have investigated the DOX nuclear accumulation by using either DOX fluorescence or indirect labeling techniques, showing an intimate relationship between DOX nuclear accumulation and its cellular concentration.(68) However, those approaches present some limitations, as DOX fluorescence can be influenced when it intercalates with DNA and the mechanism of action of dyes used to probe, for example DNA content (55), are unclear and can interfere with the process itself.(69, 70) No relationship between nuclear DOX accumulation and its cellular effects has been clearly defined. In contrast, using Raman micro spectroscopy as an in vitro label free tool to investigate drug kinetics and pharmacodynamics, coupled with multivariate data analysis, shows the DOX cellular distribution, interactions and effects.It appears that the early stage responses are dominated by the kinetics of the chemotherapeutic drug accumulation, principally in the nucleolar region, and by the DOXDNA interaction. Notably, the observed changes in these early stages are predominantly associated with RNA, rather than DNA, changes to which become more prominent in the interactions in the nuclear region. At later stages, when the localised DOX concentration has reached the saturation point, the cellular response to DOX treatment becomes prominent. Saturation of the nucleolar region prior to the nuclear highlights again the importance of this subcellular region, not only in the cancer process but also in chemotherapy and cellular resistance, since it is the first to be targetted by DOX and as a consequence the first to react to drug exposure, followed by the nucleus and finally by the cytoplasm after $48 \mathrm{hrs}$ exposure. The observation that appreciable accumulation of DOX in the cytoplasm is only apparent after such prolonged exposure times may have implications on the relative contributions of alternatives routes towards cell death based on oxidative stress in the cytoplasm.(71) 


\section{Conclusion:}

The Food and Drug Administration classifies DOX as one of the most effective chemotherapeutic drug worldwide used for the treatment of various cancers. $(1,7)$ Nevertheless, it presents serious clinical side effects and its full mechanism of action is still not completely understood. For this a development of an in vitroscreening method to detect drugs inside cells and map their mechanism of action and the cellular response is of critical importance.

In the present work, Raman micro spectroscopy associated with multivariate data analysis (PCA, PLSR and ICA) has been demonstrated to be capable of not only monitoring the subcellular accumulation and distribution of the drug inside cells and elucidating the mechanism of action, but also differentiating, as a function of time, the subsequent cellular response. It is notable that the nucleolus is the first to be saturated by DOX and it is the first cellular compartment to be affected and to react to this treatment, highlighting the importance of this organelle in cancer development and in cancer therapy.

The profile of spectroscopic responses is complex, being a label free combinatorial response of the affected biochemcial constituents in each region. Nevertheless, that profile is well defined in terms of subcellular region and temporal evolution, indicating the potential of the technique as an in vitro, pre-clinical screening technique for drug efficacy and mode of action. Exploring differences in responses could ultimately elucidate meachnisms ofcellular resistance, towards applications in companion diagnostics.

\section{Compliance with Ethical Standards:}

"The authors certify that there is no conflict of interest and they have no affiliations with or involvement in any organization or entity with any financial or non-financial interest"

\section{Acknowledgement:}

This work was supported by Science Foundation Ireland Principle Investigator Award 11/PI/1108. 


\section{References:}

1. Carvalho C, Santos RX, Cardoso S, Correia S, Oliveira PJ, Santos MS, et al. Doxorubicin: the good, the bad and the ugly effect. Current medicinal chemistry. 2009;16(25):3267-85.

2. Mitry MA, Edwards JG. Doxorubicin induced heart failure: Phenotype and molecular mechanisms. IJC Heart \& Vasculature. 2016;10:17-24.

3. Carvalho FS, Burgeiro A, Garcia R, Moreno AJ, Carvalho RA, Oliveira PJ. Doxorubicin-induced cardiotoxicity: from bioenergetic failure and cell death to cardiomyopathy. Medicinal research reviews. 2014;34(1):106-35.

4. Hofman J, Skarka A, Havrankova J, Wsol V. Pharmacokinetic interactions of breast cancer chemotherapeutics with human doxorubicin reductases. Biochemical pharmacology. 2015;96(3):168-78.

5. Schiller JH, Gandara DR, Goss GD, Vokes EE. Non-small-cell lung cancer: then and now. Journal of clinical oncology : official journal of the American Society of Clinical Oncology. 2013;31(8):981-3.

6. Umsumarng S, Pitchakarn P, Sastraruji K, Yodkeeree S, Ung AT, Pyne SG, et al. Reversal of Human Multi-Drug Resistance Leukaemic Cells by Stemofoline Derivatives via Inhibition of P-Glycoprotein Function. Basic \& Clinical Pharmacology \& Toxicology. 2015;116(5):390-7.

7. Tacar O, Sriamornsak P, Dass CR. Doxorubicin: an update on anticancer molecular action, toxicity and novel drug delivery systems. The Journal of pharmacy and pharmacology. 2013;65(2):157-70.

8. Golunski G, Borowik A, Derewonko N, Kawiak A, Rychlowski M, Woziwodzka A, et al. Pentoxifylline as a modulator of anticancer drug doxorubicin. Part II: Reduction of doxorubicin DNA binding and alleviation of its biological effects. Biochimie. 2016;123:95102.

9. Akhter MZ, Rajeswari MR. Interaction of doxorubicin with a regulatory element of hmgal and its in vitro anti-cancer activity associated with decreased HMGA1 expression. Journal of photochemistry and photobiology B, Biology. 2014;141:36-46.

10. Burger K, Muhl B, Harasim T, Rohrmoser M, Malamoussi A, Orban M, et al. Chemotherapeutic drugs inhibit ribosome biogenesis at various levels. The Journal of biological chemistry. 2010;285(16):12416-25. 
11. El-Awady RA, Semreen MH, Saber-Ayad MM, Cyprian F, Menon V, Al-Tel TH. Modulation of DNA damage response and induction of apoptosis mediates synergism between doxorubicin and a new imidazopyridine derivative in breast and lung cancer cells. DNA repair. 2016;37:1-11.

12. Farhane Z, Bonnier F, Maher MA, Bryant J, Casey A, Byrne HJ. Differentiating responses of lung cancer cell lines to Doxorubicin exposure: in vitro Raman micro spectroscopy, oxidative stress and bcl-2 protein expression. Journal of biophotonics. 2016.

13. Yadav N, Pliss A, Kuzmin A, Rapali P, Sun L, Prasad P, et al. Transformations of the macromolecular landscape at mitochondria during DNA-damage-induced apoptotic cell death. Cell death \& disease. 2014;5:e1453.

14. Quin JE, Devlin JR, Cameron D, Hannan KM, Pearson RB, Hannan RD. Targeting the nucleolus for cancer intervention. Biochimica et biophysica acta. 2014;1842(6):802-16.

15. Lo SJ, Lee CC, Lai HJ. The nucleolus: reviewing oldies to have new understandings. Cell research. 2006;16(6):530-8.

16. Hein N, Hannan KM, George AJ, Sanij E, Hannan RD. The nucleolus: an emerging target for cancer therapy. Trends in molecular medicine. 2013;19(11):643-54.

17. Orsolic I, Jurada D, Pullen N, Oren M, Eliopoulos AG, Volarevic S. The relationship between the nucleolus and cancer: Current evidence and emerging paradigms. Seminars in cancer biology. 2016;37-38:36-50.

18. Woods SJ, Hannan KM, Pearson RB, Hannan RD. The nucleolus as a fundamental regulator of the p53 response and a new target for cancer therapy. Biochimica et Biophysica Acta (BBA) - Gene Regulatory Mechanisms. 2015;1849(7):821-9.

19. Farhane Z, Bonnier F, Casey A, Maguire A, O'Neill L, Byrne HJ. Cellular discrimination using in vitro Raman micro spectroscopy: the role of the nucleolus. Analyst. 2015;140(17):5908-19.

20. Bolukbas DA, Meiners S. Lung cancer nanomedicine: potentials and pitfalls. Nanomedicine (London, England). 2015;10(21):3203-12.

21. Huser T, Chan J. Raman spectroscopy for physiological investigations of tissues and cells. Advanced Drug Delivery Reviews. 2015;89:57-70.

22. Byrne JH, Ostrowska MK, Nawaz H, Dorney J, Meade DA, Bonnier F, et al. Vibrational Spectroscopy: Disease Diagnostics and Beyond. In: Baranska M, editor. Optical Spectroscopy and Computational Methods in Biology and Medicine. 14. Dordrecht: Springer Netherlands; 2014. p. 355-99. 
23. Gala U, Chauhan H. Principles and applications of Raman spectroscopy in pharmaceutical drug discovery and development. Expert opinion on drug discovery. 2015;10(2):187-206.

24. Notingher I. Raman Spectroscopy Cell-based Biosensors. Sensors (Basel, Switzerland). 2007;7(8):1343-58.

25. Vankeirsbilck T, Vercauteren A, Baeyens W, Van der Weken G, Verpoort F, Vergote G, et al. Applications of Raman spectroscopy in pharmaceutical analysis. TrAC Trends in Analytical Chemistry. 2002;21(12):869-77.

26. Bhumika DP, Priti JM. An Overview: Application of Raman Spectroscopy in Pharmaceutical Field. Current Pharmaceutical Analysis. 2010;6(2):131-41.

27. Kallaway C, Almond LM, Barr H, Wood J, Hutchings J, Kendall C, et al. Advances in the clinical application of Raman spectroscopy for cancer diagnostics. Photodiagnosis and Photodynamic Therapy. 2013;10(3):207-19.

28. Pence I, Mahadevan-Jansen A. Clinical instrumentation and applications of Raman spectroscopy. Chemical Society reviews. 2016;45(7):1958-79.

29. Farhane Z, Bonnier F, Casey A, Byrne HJ. Raman micro spectroscopy for in vitro drug screening: subcellular localisation and interactions of doxorubicin. Analyst. 2015;140(12):4212-23.

30. Jorgensen JT. Clinical application of companion diagnostics. Trends in molecular medicine. 2015;21(7):405-7.

31. Trusheim MR, Berndt ER. The clinical benefits, ethics, and economics of stratified medicine and companion diagnostics. Drug Discov Today. 2015;20(12):1439-50.

32. Suggitt M, Bibby MC. 50 years of preclinical anticancer drug screening: empirical to target-driven approaches. Clinical cancer research : an official journal of the American Association for Cancer Research. 2005;11(3):971-81.

33. Zhang D, Luo G, Ding X, Lu C. Preclinical experimental models of drug metabolism and disposition in drug discovery and development. Acta Pharmaceutica Sinica B. 2012;2(6):549-61.

34. Bonnier F, Byrne HJ. Understanding the molecular information contained in principal component analysis of vibrational spectra of biological systems. The Analyst. 2012;137(2):322-32.

35. Muratore M. Raman spectroscopy and partial least squares analysis in discrimination of peripheral cells affected by Huntington's disease. Analytica chimica acta. 2013;793:1-10. 
36. Keating ME, Nawaz H, Bonnier F, Byrne HJ. Multivariate statistical methodologies applied in biomedical Raman spectroscopy: assessing the validity of partial least squares regression using simulated model datasets. The Analyst. 2015;140(7):2482-92.

37. Nawaz H, Bonnier F, Meade AD, Lyng FM, Byrne HJ. Comparison of subcellular responses for the evaluation and prediction of the chemotherapeutic response to cisplatin in lung adenocarcinoma using Raman spectroscopy. The Analyst. 2011;136(12):2450-63.

38. Boiret M, Rutledge DN, Gorretta N, Ginot YM, Roger JM. Application of independent component analysis on Raman images of a pharmaceutical drug product: pure spectra determination and spatial distribution of constituents. Journal of pharmaceutical and biomedical analysis. 2014;90:78-84.

39. Parastar H, Jalali-Heravi M, Tauler R. Is independent component analysis appropriate for multivariate resolution in analytical chemistry? TrAC Trends in Analytical Chemistry. 2012;31:134-43.

40. Wang G, Ding Q, Hou Z. Independent component analysis and its applications in signal processing for analytical chemistry. TrAC Trends in Analytical Chemistry. 2008;27(4):368-76.

41. Green PS, Leeuwenburgh C. Mitochondrial dysfunction is an early indicator of doxorubicin-induced apoptosis. Biochimica et biophysica acta. 2002;1588(1):94-101 .

42. Berthiaume JM, Wallace KB. Adriamycin-induced oxidative mitochondrial cardiotoxicity. Cell biology and toxicology. 2007;23(1):15-25.

43. Akbari R, Javar HJ. Efficacy of Capecitabine and 5- Fluorouracil (5-FU)on the human breast cancer cell line (MCF7) - effect of concentration. Am J Res commun. 2013;1:6.

44. Sieuwerts AM, Klijn JG, Peters HA, Foekens JA. The MTT tetrazolium salt assay scrutinized: how to use this assay reliably to measure metabolic activity of cell cultures in vitro for the assessment of growth characteristics, IC50-values and cell survival. European journal of clinical chemistry and clinical biochemistry : journal of the Forum of European Clinical Chemistry Societies. 1995;33(11):813-23.

45. Twentyman PR, Luscombe M. A study of some variables in a tetrazolium dye (MTT) based assay for cell growth and chemosensitivity. British journal of cancer. 1987;56(3):27985 .

46. Sardao VA, Oliveira PJ, Holy J, Oliveira CR, Wallace KB. Morphological alterations induced by doxorubicin on H9c2 myoblasts: nuclear, mitochondrial, and cytoskeletal targets. Cell biology and toxicology. 2009;25(3):227-43. 
47. Olson MO, Dundr M, Szebeni A. The nucleolus: an old factory with unexpected capabilities. Trends in cell biology. 2000;10(5):189-96.

48. Glitsch M. Essentials of cell physiology. Surgery (Oxford). 2016.

49. Verrier S, Notingher I, Polak JM, Hench LL. In situ monitoring of cell death using Raman microspectroscopy. Biopolymers. 2004;74(1-2):157-62.

50. Guo J, Cai W, Du B, Qian M, Sun Z. Raman spectroscopic investigation on the interaction of malignanthepatocytes with doxorubicin. Biophysical Chemistry. 2009;140(13):57-61.

51. Notingher I, Verrier S, Haque S, Polak JM, Hench LL. Spectroscopic study of human lung epithelial cells (A549) in culture: living cells versus dead cells. Biopolymers. 2003;72(4):230-40.

52. Wallace KB. Doxorubicin-induced cardiac mitochondrionopathy. Pharmacology \& toxicology. 2003;93(3):105-15.

53. Eom YW, Kim MA, Park SS, Goo MJ, Kwon HJ, Sohn S, et al. Two distinct modes of cell death induced by doxorubicin: apoptosis and cell death through mitotic catastrophe accompanied by senescence-like phenotype. Oncogene. 2005;24(30):4765-77.

54. El-Kareh AW, Secomb TW. Two-mechanism peak concentration model for cellular pharmacodynamics of Doxorubicin. Neoplasia (New York, NY). 2005;7(7):705-13.

55. Zenebergh A, Baurain R, Trouet A. Cellular pharmacology of detorubicin and doxorubicin in L1210 cells. European journal of cancer \& clinical oncology. 1984;20(1):11521.

56. Matthews Q, Jirasek A, Lum J, Duan X, Brolo AG. Variability in Raman spectra of single human tumor cells cultured in vitro: correlation with cell cycle and culture confluency. Applied spectroscopy. 2010;64(8):871-87.

57. Kann B, Offerhaus HL, Windbergs M, Otto C. Raman microscopy for cellular investigations - From single cell imaging to drug carrier uptake visualization. Advanced Drug Delivery Reviews. 2015;89:71-90.

58. Boulon S, Westman BJ, Hutten S, Boisvert FM, Lamond AI. The nucleolus under stress. Molecular cell. 2010;40(2):216-27.

59. Movasaghi Z, Rehman S, Rehman IU. Raman Spectroscopy of Biological Tissues. Applied Spectroscopy Reviews. 2007;42(5):493-541.

60. Dellaire G, Bazett-Jones DP. Beyond repair foci: subnuclear domains and the cellular response to DNA damage. Cell cycle (Georgetown, Tex). 2007;6(15):1864-72. 
61. Moritz TJ, Taylor DS, Krol DM, Fritch J, Chan JW. Detection of doxorubicininduced apoptosis of leukemic T-lymphocytes by laser tweezers Raman spectroscopy. Biomedical Optics Express. 2010;1(4):1138-47.

62. Fadok VA, Bratton DL, Frasch SC, Warner ML, Henson PM. The role of phosphatidylserine in recognition of apoptotic cells by phagocytes. Cell death and differentiation. 1998;5(7):551-62.

63. Kagan VE, Fabisiak JP, Shvedova AA, Tyurina YY, Tyurin VA, Schor NF, et al. Oxidative signaling pathway for externalization of plasma membrane phosphatidylserine during apoptosis. FEBS letters. 2000;477(1-2):1-7.

64. Maxfield FR, Tabas I. Role of cholesterol and lipid organization in disease. Nature. 2005;438(7068):612-21.

65. Tabas I. Apoptosis and plaque destabilization in atherosclerosis: the role of macrophage apoptosis induced by cholesterol. Cell death and differentiation. 2004;11 Suppl $1:$ S12-6.

66. Yang F, Teves SS, Kemp CJ, Henikoff S. Doxorubicin, DNA torsion, and chromatin dynamics. Biochim Biophys Acta. 2014;1845(1):84-9.

67. Cummings J, Bartoszek A, Smyth JF. Determination of covalent binding to intact DNA, RNA, and oligonucleotides by intercalating anticancer drugs using high-performance liquid chromatography. Studies with doxorubicin and NADPH cytochrome P-450 reductase. Anal Biochem. 1991;194(1):146-55.

68. Gigli M, Doglia SM, Millot JM, Valentini L, Manfait M. Quantitative study of doxorubicin in living cell nuclei by microspectrofluorometry. Biochimica et biophysica acta. 1988;950(1):13-20.

69. Hovorka O, Subr V, Vetvicka D, Kovar L, Strohalm J, Strohalm M, et al. Spectral analysis of doxorubicin accumulation and the indirect quantification of its DNA intercalation. European journal of pharmaceutics and biopharmaceutics : official journal of Arbeitsgemeinschaft fur Pharmazeutische Verfahrenstechnik eV. 2010;76(3):514-24.

70. Karukstis KK, Thompson EH, Whiles JA, Rosenfeld RJ. Deciphering the fluorescence signature of daunomycin and doxorubicin. Biophysical chemistry. 1998;73(3):249-63.

71. Gewirtz D. A critical evaluation of the mechanisms of action proposed for the antitumor effects of the anthracycline antibiotics adriamycin and daunorubicin. Biochemical Pharmacology. 1999;57(7):727-41. 
